\begin{tabular}{|l|l|}
\hline Las ciudades y la cuestión social & Titulo \\
\hline Ziccardi, Alicia - Autor/a & Autor(es) \\
\hline $\begin{array}{l}\text { Pobreza, desigualdad social y ciudadanía. Los límites de las políticas sociales en } \\
\text { América Latina }\end{array}$ & En: \\
\hline Buenos Aires & Lugar \\
\hline CLACSO, Consejo Latinoamericano de Ciencias Sociales & Editorial/Editor \\
\hline 2001 & Fecha \\
\hline $\begin{array}{l}\text { Segmentacion social; Ciudadania; Pobreza Urbana; Exclusion Social; Politica Urbana; } \\
\text { Politica Social; Desigualdad social; Empleo; Pobreza; Poblacion urbana; Ciudades; } \\
\text { Inseguridad; Violencia urbana; America Latina ; }\end{array}$ & Telección \\
\hline Capítulo de Libro & \\
\hline http://bibliotecavirtual.clacso.org.ar/clacso/gt/20101029064541/7verdera.pdf & Tipo de documento \\
\hline $\begin{array}{l}\text { Reconocimiento-No comercial-Sin obras derivadas 2.0 Genérica } \\
\text { http://creativecommons.org/licenses/by-nc-nd/2.0/deed.es }\end{array}$ & Licencia \\
\hline
\end{tabular}

Segui buscando en la Red de Bibliotecas Virtuales de CLACSO http://biblioteca.clacso.edu.ar

Consejo Latinoamericano de Ciencias Sociales (CLACSO)

Conselho Latino-americano de Ciências Sociais (CLACSO)

Latin American Council of Social Sciences (CLACSO)

www.clacso.edu.ar
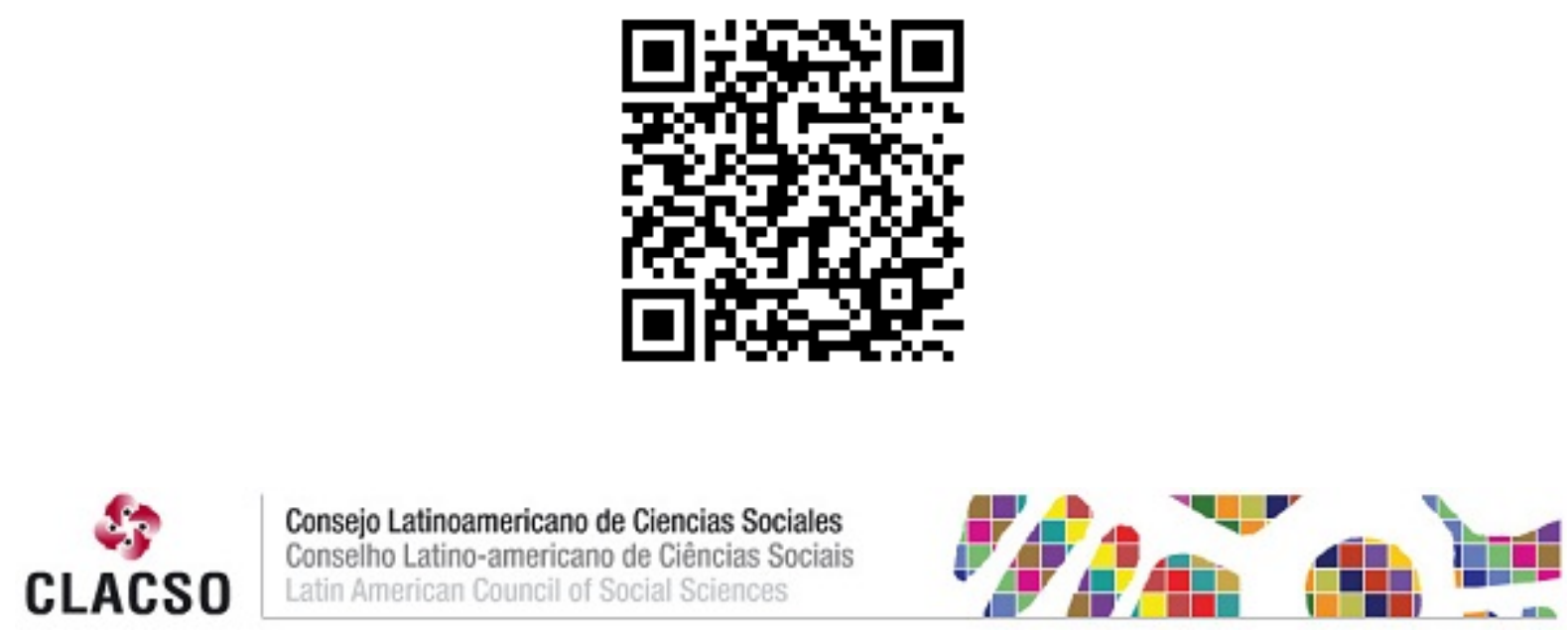


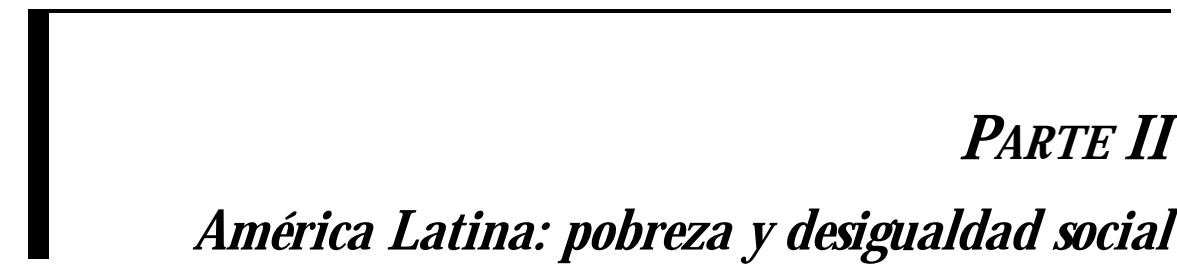





\section{Las ciudades y la cuestión social *}

\section{$\approx$ Alicia Ziccardi *}

"La difusión de la tecnología de la información en la economía no induce directamente el desempleo y puede crear más puestos de trabajo a largo plazo. La transformación de la gestión y el trabajo mejora la estructura ocupacional en mayor medida que aumenta el número de puestos de trabajo de baja calificación. El incremento del comercio y la inversión globa les no parece ser, por sí mismo, un factor causal importante en la elimina ción de puestos de trabajo y la degradación de las condiciones laborales en el Norte, mientras que contribuye a crear millones de puestos de trabajo en los países de reciente industrialización. $Y$, no obstante, el proceso de transición histórica hacia una sociedad informacional y una economía global se caracteriza por el deterioro extendido de las condiciones de vida y trabajo para la clase trabajadora"

Manuel Castells (1997)

\section{La cuestión social al fin del milenio: una introducción}

a cuestión social surge como tal a fines del siglo XIX cuando el capitalismo comenzaba a ceder ante las luchas protagonizadas por las primeras organizaciones sindicales para mejorar su salario y las pésimas condiciones que prevalecían en el espacio de la producción (la fábrica) y de la habitación. El liberalismo había colocado en los individuos la capacidad de resolver su propia supervivencia propugnando la abstención del estado y reservando la atención de la pobreza a las instituciones de beneficencia o caridad. Pero la constitución de los estados nacionales, la diferenciación de la sociedad en clases, la creación de una institucionalidad gubernamental burocrática y el germen del estado benefactor que asume la responsabilidad de proveer bienes y servicios básicos al conjunto de la población, serán los principales rasgos de la relación estado-sociedad,

* Este trabajo forma parte de los trabajos elaborados para la realización del documento de lanzamien to de la Red no 5 URBALde la Unión Europea, cuya sede es la Municipalidad de Montevideo.

** Licenciada y Maestra en Sociología. Dra. en Economía. Investigadora Titular del Instituto de Investigaciones Sociales de la UNAM. Coordinadora del área Sociología Urbana y Regional del IISUNAM. Miembro del Sistema Nacional de Investigadores. Coordinadora del Grupo de Trabajo sobre "Pobreza y Políticas Sociales" de CLACSO. 
que finalmente se consolida después de la segunda guerra mundial. Es entonces cuando se desarrolla el estado de bienestar, y la cuestión social, incluida en la agenda gubernamental, sustenta la necesidad de diseñar e implementar políticas sociales.

Las políticas sociales son la garantía de que se busca la equidad social y la promoción de los derechos básicos de la ciudadanía. Por ello es algo muy diferente la política de reducción de la pobreza, que busca sacar de la condición de miseria a quienes aún no han alcanzado el piso básico de la supervivencia (Abranches, et. 1994: p. 14). Estas últimas, y algunas de las políticas sociales como educación, salud e inclusive las urbanas, fueron en sus orígenes competencia del gobierno nacional, aunque los recientes procesos de descentralización tienden a traspasar su operación a los gobiernos locales (estatal o municipal).

Precisamente, las reflexiones contenidas en este trabajo observan la cuestión social desde la perspectiva del ámbito local. Aún reconociendo que en las ciudades actúan diferentes ámbitos de gobierno (nacional, regional, provincial o estatal) el principal objetivo de este trabajo es abordar aquellas cuestiones sociales que están presentes en el diseño y en las actuaciones gubernamentales de las instituciones de gobierno local, las cuales forman parte de las llamadas "políticas sociales urbanas".

Por otra parte, en la ciudad la cuestión social atiende diferentes clientelas o grupos sociales (asalariados, pobres, mujeres, niños, jóvenes, ancianos) e incide en muy variados procesos de la vida social, tales como: el acceso diferencial a la educación y salud; las condiciones de precariedad e informalidad en el empleo, las formas de pertenencia a sistemas de seguridad social, la vulnerabilidad social y territorial, la violencia e inseguridad, la construcción y expansión de la ciudadanía, la sustentabilidad ambiental. Todas éstas son cuestiones que dan origen a formas de intervención o participación de instituciones gubernamentales las cuales suelen cumplir una función redistributiva al garantizar el acceso a bienes y servicios básicos independientemente de la capacidad de apropiación que tengan los individuos en el mercado ${ }^{1}$.

Dice la convocatoria al debate de la Red sobre las Políticas Sociales Urbanas (1998: p. 15) que "para la definición de las políticas sociales urbanas, es imprescindible identificar las nuevas desigualdades y pautas de diferenciación socioeconómica en la ciudad”, es decir, ¿qué es lo que caracteriza a la/s cuestión/es socia1/es de la ciudad del fin de milenio?

En primer lugar, debe señalarse que al fin del milenio el mundo avanza inexorablemente hacia la urbanización. Pero se trata de una urbanización muy diferente a la experimentada a principios y mediados de este siglo, porque en estas dos últimas décadas las ciudades han sido confrontadas a intensos procesos que han modificado no sólo su fisonomía sino su propia naturaleza, porque lo que se 
ha modificado es su sociedad. Por ello puede decirse que estamos en el umbral de una nueva etapa, caracterizada porque las relaciones entre sociedad y territorio son cualitativamente diferentes a las que surgieron con el desarrollo de la ciudad manufacturera (Ziccardi, 1998 [b]). Los procesos que han contribuido a esto, y que enmarcan la transformación de las cuestiones sociales y políticas urbanas, son:

Los procesos de globalización de la economía que han disminuido la importancia de la localización espacial para la realización de las actividades productivas en el territorio, ya que los flujos y redes de capital tienden a flexibilizar y a la vez desterritorializar el proceso productivo. La principal consecuencia para las grandes ciudades es el protagonizar un irreversible proceso de desindustrialización y terciarización de su economía. Esto se ha traducido en un número cada vez menor de empleos estables y bien remunerados y en la proliferación de actividades informales, de las cuales el comercio ambulante en los centros y en las calles de las grandes ciudades del mundo se halla a la vista de cualquier observador (Castells,1997; Borja y Castells, 1997; Coraggio,1998 [a]; Ziccardi, 1995 [a]). Esta transformación económica ha modificado en su fisonomía y en su sustancia la cuestión social.

La reforma del estado de bienestar, aunque sea como modelo nunca plenamente desarrollado en los países latinoamericanos, que afecta principalmente los procesos de gestión gubernamental de bienes y servicios urbanos. Las ciudades deben reestructurar las políticas sociales, entre éstas las políticas urbanas, puesto que disminuyen los recursos y acciones de los gobiernos nacionales sobre el territorio, lo cual obliga a los locales a generar más ingresos propios a través de expandir e incrementar los gravámenes fiscales y establecer nuevas formas de relación entre lo público y lo privado para el suministro de servicios urbanos. La cuestión social parece expandirse, mientras que la acción estatal se retrae y se transfieren cada vez más responsabilidades a la sociedad.

La revolución informacional que ha creado nuevas tecnologías que acortan las distancias, desdibujan el rol que tradicionalmente asumieron las ciudades, y transmiten una cultura globalizada a través de un sistema de comunicación internacionalmente operado. Esto contribuye a homogeneizar los gustos, las preferencias y el mismo paisaje urbano, pero paradójicamente, ha reforzado la identidad de las sociedades locales (García Canclini, 1995; Castells, 1996; Safa, 1998; García Canclini, 1998). La cuestión social se internacionaliza en el imaginario colectivo, ya que las necesidades y conflictos tienden a compartirse no obstante las diferencias nacionales y regionales. Su atención se remite a las agencias gubernamentales, aunque cada vez más se amplía el espacio de actuación de las organizaciones de la sociedad civil.

A estas tres transformaciones de nivel internacional, se agregan en América Latina: 
La profundización de los procesos de democratización del sistema político, cuyos efectos conllevan, entre otras cosas, la transformación de la forma de gobierno de las ciudades y la expansión de la ciudadanía política y social. La alternancia y el pluralismo político hacen su aparición en las ciudades, las cuales poseen un caudal electoral por el que compiten los diferentes partidos políticos ${ }^{2}$, pero a la vez renuevan y acrecientan las expectativas de los sectores populares respecto a la atención de sus postergadas demandas.

El gran desafío es ahora construir la democracia social en la cotidianeidad, a través de nuevas relaciones entre gobierno y ciudadanía. Para ello, sin duda es un requisito fundamental crear nuevas formas de participación ciudadana que garanticen la inclusión de los intereses de la sociedad en los procesos decisorios de las instituciones gubernamentales. Esto es, restituir el carácter público a la acción gubernamental creando nuevas formas de gestión para atender la cuestión social, que en las ciudades corresponden a las instituciones encargadas de formular e implementar las políticas sociales. Es allí donde se instalan las principales bases para la construcción de una gobernabilidad democrática que sustente un nuevo estilo de gobierno y de gestión en las ciudades latinoamericanas (Ziccardi, 1998 [b]).

Ahora bien, la complejidad de la cuestión social en las ciudades, tanto latinoamericanas como europeas, obliga a seleccionar aquellos temas más relevantes para dar inicio a un debate, los cuales se presentarán en cuatro apartados. El primero es el que analiza los rasgos más sobresalientes de la dinámica poblacional urbana, la cual permite aproximarnos al conocimiento del universo en el que se define la cuestión social.

\section{La dinámica poblacional urbana}

Según la ONU (1997) a mediados de 1996 la población mundial era de 5.770 millones de habitantes y el $80 \%$ vivía en las regiones menos desarrolladas, en las cuales se advierte en las últimas décadas un fuerte crecimiento urbano (Gilbert, 1993).

El crecimiento demográfico actual es el más bajo desde la Segunda Guerra Mundial. Así, mientras la tasa de crecimiento demográfico en Europa entre 1950 y 1955 fue de 1 y la de América Latina y el Caribe de 2,7, en el último quinquenio (1990-1995) ambas se redujeron a 0,2 y 1,7 respectivamente $^{3}$.

Pero cabe destacar que Europa es la única gran zona cuya tasa de crecimiento anual fue inferior al 1\% en la segunda mitad de este siglo (1950-1995), descenso que se aprecia más en Luxemburgo, Bélgica y Dinamarca. En Europa occidental se registran las tasas más elevadas como consecuencia de las crecientes migraciones (sobre todo en Alemania), mientras que decrecen en Europa oriental como consecuencia de la emigración, los bruscos descensos de la fecundidad y una cre- 
ciente o estacionaria mortalidad, producto de las guerras que se han dado en esta área. En Europa meridional se registra un fuerte descenso de la tasa de fecundidad, y en Europa septentrional ésta es similar a la media (ONU, 1997: pp. 22-23).

La tasa de fecundidad más baja de Europa es la de Italia $(1,2)$, y la más alta la de Albania $(2,9)$. La mortalidad tiende a decrecer en la mayoría de los países pero tiene sus niveles más bajos en Europa.

Respecto a esto último, Pierre Rosanvallon (1995: p. 41), haciendo referencia a la situación francesa (la cual tal vez puede extenderse a varios países de la Unión Europea), analiza los efectos que tuvo la llamada revolución demográfica sobre la seguridad social. En particular, el alargamiento de la duración de la vida y la reducción de la natalidad afectan a uno de sus mecanismos básicos del seguro social -la transferencia entre generaciones-, lo cual provoca desequilibrios en la disponibilidad de recursos para los inactivos y para las prestaciones. Por ello, ésta es una de las principales temáticas que forman parte de la "nueva cuestión social".

Una segunda cuestión poblacional es la vinculada a la migración internacional, que en 1990 acogió a 24 millones de migrantes internacionales que llegan a las ciudades y necesitan desarrollar alguna actividad remunerada para garantizar su supervivencia, generando presiones sobre el mercado de trabajo, mayor informalidad, y precariedad en el empleo (ONU, 1997 [a]: p. 30). Dos son los principales tipos de este significativo crecimiento poblacional este-oeste:

a) Una migración económica en busca de empleo procedente de países del entorno inmediato de la comunidad (Turquía en primer lugar y luego Túnez, Marruecos, Argelia), a los que se agregan los de la propia comunidad (Grecia, España, Italia, Portugal e Irlanda) que migran hacia regiones más industrializadas (Alemania, Francia, Holanda, Bélgica, y Reino Unido). Estos últimos han sido particularmente importantes en los setenta y ochenta y actualmente son más moderados (Alburquerque, 1993: p. 64).

b) Una migración política, que es producto de los cambios en el orden geopolítico mundial como consecuencia de los conflictos que suscitaron la desintegración de algunos Estados, en particular la antigua Yugoslavia, cuya disolución ha desencadenado un conflicto armado en Croacia, Bosnia y Herzegovina. Esto generó víctimas de guerra que buscaron protección, y que ACNUR estimó en 1994 en 3,8 millones. Ante esta nueva problemática social países como Alemania y Grecia crearon categorías de migrantes para recibir a quienes eran originarios de los mismos. Austria, Hungría, Suecia, Suiza y Turquía también ofrecieron asilo.

Todos estos movimientos de población generan efectos urbanos, que obligan a reconocer la presencia de un nuevo tipo de ciudadano, una fuerza de trabajo disponible que a la vez demanda bienes y servicios en la ciudad. 
La dinámica poblacional en América Latina es muy diferente. A principio de los noventa se estimaba que la población urbana en América Latina era del orden del $70 \%$ del total. Sin embargo, el ritmo del crecimiento urbano tiende a bajar en la última década: mientras que entre 1965 y 1980 la tasa de crecimiento urbano fue de 3,9, entre 1980 y 1990 fue del 3\% (Gilbert, 1993: pp. 42-43). Esto es consecuencia de la caída de las tasas de fertilidad y la disminución del crecimiento natural. En el área existen tasas de fecundidad medias relativamente uniformes, y es América Central la zona que registra el mayor descenso, ya que en los ' 90 pasó de 4,5 a 3,4.

La esperanza de vida en América Latina es de 68,5, marcadamente menor que la de Europa, que es de 72,7 (exceptuando a Europa Oriental) (ONU, 1997 [a]), lo cual debe atribuirse principalmente a la pobreza, la desnutrición y el hambre, que son la principal causa de las enfermedades gastrointestinales, propias de la falta de servicios sanitarios, drenaje, agua potable, etc. A ello se agrega que el porcentaje de población con SIDA es de más del 9\% del total de los 3 millones de casos que registra la OMS a escala mundial.

Mientras las ciudades latinoamericanas del sur -Montevideo o Buenos Aires (Capital)- presentan una dinámica poblacional bastante más cercana a la europea, otras como Ciudad de México o São Paulo muestran aun una elevada tasa de crecimiento y un predominio de población joven e infantil. Ello, sumado al incremento de la esperanza de vida, se traduce en un fuerte peso de la población inactiva sobre la activa.

En cuanto a la migración internacional, continúa el flujo de migrantes de México a EUA, los cuales migraron fundamentalmente buscando oportunidades de empleo, la mayoría sin poseer la documentación que se requiere ${ }^{4}$. En muchos casos sus familias permanecen en México, y esta migración permite que se transfiera un elevado monto de dinero de manera periódica hacia los lugares de origen de los migrantes. Sin embargo, esta migración no es suficiente para descomprimir la presión que ejerce la mano de obra joven que se incorpora anualmente al mercado de empleo. Por ello, las ciudades son para estos trabajadores la principal fuente de empleo, aunque ofrezcan precariedad e informalidad y registren también elevadas tasas de desempleo.

En Centroamérica, la migración no sólo es económica, sino también consecuencia de los conflictos armados de las últimas décadas. La misma se dirige principalmente a Estados Unidos y México, y la mayoría de los migrantes lo hace en situaciones de absoluta precariedad e ilegalidad. En 1990 se registraban en EUA20 millones, de los cuales 3 millones eran indocumentados. En América del Sur, en cambio, la migración es intra-regional, y no se advierten cambios durante las últimas décadas (ONU, 1997 [a]). 
Esta situación poblacional impone nuevas características a la cuestión social y genera diferentes problemas en las ciudades latinoamericanas, tales como: i) un fuerte peso de la población inactiva sobre la activa; ii) una creciente demanda de empleos y de bienes y servicios colectivos (salud, educación, deportes, cultura) que debe ser atendida por las instituciones gubernamentales a pesar de las recientes tendencias a la privatización, iii) una carga mayor sobre la seguridad social en materia de jubilaciones en un contexto de descapitalización de los fondos tras varias décadas de procesos inflacionarios grave y iv) un proceso de urbanización, feminización e infantilización de la pobreza, los cuales son consecuencia no sólo de la dinámica demográfica, sino principalmente de las modalidades que posee el empleo urbano y que se expondrán seguidamente.

\section{El empleo urbano y la nueva cuestión social}

\section{El empleo y la informalidad}

Desde la perspectiva de la cuestión social puede decirse que en las ciudades europeas el principal problema que afecta a la fuerza de trabajo urbana es el desempleo. El paro es la principal causa de la pobreza. Ya a comienzos de los ochenta el desempleo sobrepasaba el 10\% en Francia, Bélgica y Reino Unido y unos pocos años después se llegó a registrar un $25 \%$ en numerosas ciudades, e incluso se superó este porcentaje en ciudades vecinas a las grandes aglomeraciones urbanas. Las ciudades españolas fueron las que más altos niveles de desempleo alcanzaron en el sur de Europa, seguidas por las portuguesas y las griegas. En los '90 esta situación persiste, aunque mejoró. Esto ha producido un conjunto social de nuevos pobres, que son aquellos desempleados de larga duración, como consecuencia de los cambios estructurales de la economía y de las migraciones de regiones periféricas de Europa, África, Asia, y Europa Oriental (Ayuntamiento de Barcelona-Eurociudades, 1991: pp. 30-31).

Esta situación pone en cuestión el mecanismo del seguro de desempleo, diseñado originalmente para una situación de excepción, con la idea de asegurar a los trabajadores temporalmente desempleados un mínimo de ingresos que garantice su supervivencia y la de su familia.

Además, en la última década, los procesos de globalización de la economía refuerzan la segmentación del mercado de trabajo urbano entre quienes se integran a las actividades del sector moderno de la economía y quienes deben aceptar una creciente precariedad e informalidad (por ejemplo, el comercio informal en la vía pública), formas de inserción que deben aceptar principalmente los migrantes.

En América Latina se registran en las ciudades elevadas tasas de desempleo, subempleo, y un elevado grado de informalidad, que es el principal rasgo del 
mercado de trabajo urbano en la región. Este último fenómeno es cuantitativamente importante en ciudades como Lima, Ciudad de México, São Paulo y Buenos Aires, en las que sus economías han experimentado un proceso de pérdida de empleos asalariados al disminuir la actividad industrial. Un análisis reciente de la CEPAL corrobora esto al decir que:

"El crecimiento registrado por América Latina y el Caribe en el período de la posguerra implicó una creación dinámica de empleos y una radical transformación de la fuerza de trabajo que aumentaba a razón de un 2,5\% anual. La rápida urbanización redujo la población activa empleada en el sector agrícola de un 55\% del total en 1950, a un 32\% en 1980. El empleo generado por el sector formal urbano se expandió a un $4 \%$ anual, pero este incremento resultó insuficiente para absorber a los nuevos integrantes de la fuerza de trabajo urbana, cuyo nivel de sub-utilización (desocupación o empleo en actividades informales) se mantuvo en torno al 30\% (Tokman, 1991)" (Cit. CEPAL, 1996: p. 33).

La misma fuente indica que existe una débil relación entre el crecimiento económico y la generación de empleo, y que en 1994 sólo unos pocos países (Chile y Colombia) muestran mejoría respecto de 1980, tanto en el desempleo urbano como en los salarios reales. En Brasil, México y Costa Rica el desempleo se redujo y los salarios de las actividades formales recuperaron el nivel anterior. Sólo Bolivia presentó declinación del desempleo urbano y del salario a la vez. En otros países (Argentina, Ecuador, Nicaragua, Perú y Venezuela) se advierten mayores niveles de desempleo y salarios más bajos, o en el mejor de los casos similares a 1980. Sólo Panamá presenta un aumento de salarios en el sector moderno en un contexto de mayor desempleo (CEPAL, 1996: p. 39).

Pero si bien las tasas de desempleo continúan siendo preocupantes, lo que ha crecido aun más en las ciudades es la informalidad y precariedad en el empleo, lo cual representa en promedio entre el 30 y el $50 \%$ de las actividades económicas urbanas en América Latinas. En el presente decenio la mayor parte del empleo generado corresponde al sector informal (de 100 empleos creados, 84 correspondieron a ese sector $)^{6}$. Sin duda existen diferencias nacionales extremadamente importantes entre países, pero este es un dato revelador para quienes toman decisiones en materia de política social.

Se afirma que la principal causa es la poca productividad e inversión en capital y la poca calificación de su mano de obra. De hecho, el sector informal de la economía puede definirse "como todo aquel trabajo por cuenta propia (o microempresario) o asalariado o aprendiz o familiar no remunerado en una unidad de producción, servicio o comercio con poca inversión de capital, que no emplea más de diez personas generalmente poco calificadas, totalmente o parcialmente fuera de las reglas administrativas vigentes, que utiliza el trabajo familiar no siempre remunerado y que tiene horarios de trabajos flexibles" (Vandershuren, 
1995: p. 231). En las ciudades abarca una amplia variedad de actividades, construcción informal, microempresas, parte de los servicios de reparación, alimentación y domésticos, dueñas de casa, vendedoras ocasionales de productos, etc.

Todas estas son situaciones que dejan al trabajador al margen del cumplimiento de los derechos sociales pactados por las organizaciones sindicales y/o establecidos en las leyes laborales. La contrapartida suele ser el transformarlos en un número mayor de demandantes de servicios sociales públicos, y como a la vez la tendencia es reducir el gasto social gubernamental, esto conlleva a un deterioro de la calidad de los mismos (ej. salud).

Frente a estas descripciones de las actividades informales que se desarrollan en la economía urbana, José Luis Coraggio (1998) se ubica en una perspectiva diferente al introducir la noción de economía popular, analizando cuáles son las potencialidades que ésta posee, en el interior de la economía en su conjunto, para generar bienestar a quienes están insertos en la misma. Este autor afirma que para (que) "el conjunto de las actividades económicas populares supere los efectos económicos de la exclusión que caracteriza la transición dentro del régimen capitalista al modo de desarrollo informal, es necesario combinar: a) el desarrollo de actividades colectivas de reproducción (de alto componente de voluntad), b) el desarrollo de la interdependencia mercantil (de alto componente de automaticidad), es decir de intercambios mediados por el mercado entre unidades domésticas y c) el desarrollo de su capacidad sistemática para competir con unas y utilizar otras mercancías de las empresas capitalistas" (p.7). En este párrafo Coraggio sintetiza la complejidad que encierra el desarrollo de la economía popular como una forma de producción y consumo, que puede ser una alternativa viable a poner en práctica aun en el contexto de una economía globalizada.

Lo cierto es que la situación que prevalece en el mercado de trabajo urbano es consecuencia de los procesos de desindustrialización y terciarización de la economía de las grandes ciudades, los cuales trajeron aparejada una disminución del número de empleos estables y bien remunerados que garantizaban al trabajador y a su familia el acceso a la seguridad social, a la salud, e inclusive, en algunos países, a la recreación (ej. clubes, hoteles para turismo, etc.).

En contrapartida, se expanden: 1) los servicios de la sociedad informacional que demandan alta calificación y ofrecen elevados salarios (servicios financieros y/o de la informática, comercio de grandes tiendas); 2) el terciario informal, una de cuyas principales expresiones urbanas es el comercio ambulante. Un dato interesante es que aún en aquellas ciudades medias que conservan, atraen y/o tienen nuevas actividades industriales (ej. ciudades como Querétaro, Monterrey, Puebla, León en México o las ciudades del interior de Argentina), la informalidad del comercio en la vía pública se expande, y sus centros presentan a escala características similares a los de las grandes ciudades. Sin duda, el comercio ambulante (el cual a pesar de su nombre por lo general está establecido) constituye una 
forma precaria de empleo: su principal limitación no está en el nivel de ingresos (que incluso podría ser más alto que el que se obtiene de una actividad industrial y/o estable), sino en el hecho de que su presencia en espacios públicos de las ciut dades coloca a estos trabajadores, por lo menos en un principio, en la ilegalidad. $\mathrm{Su}$ aceptación y/o reconocimiento, en el mejor de los casos, atraviesa por un proceso que suele generar un enfrentamiento con la autoridad y/o la ciudadanía.

Para las autoridades es la expresión de una actividad que escapa a las cargas fiscales, a la vez que se presenta como una competencia desleal para el comercio establecido (en precios y accesibilidad al cliente). Sin embargo, es aquí donde en nuestras ciudades el derecho al trabajo se confronta al derecho a la ciudad, ya que pone en cuestión el uso del espacio público para el conjunto de la ciudadanía y el ejercicio de la autoridad local: obstruye la circulación y la visibilidad de los negocios establecidos, generando basura y creando condiciones para que se desarrolle mayor inseguridad en la calle.

Por ello es común que los gobernantes locales surgidos de elecciones democráticas deban enfrentar en el cotidiano la disyuntiva de permitir que se ejerza el derecho al trabajo en lugares públicos destinados originalmente al esparcimiento, la recreación y la cultura, o ejercer su autoridad para que en los mismos no se realicen actividades para los que no fueron concebidos. Esta es una difícil disyuntiva, cuya resolución puede debilitar al gobierno local frente a su sociedad.

Otro dato importante sobre el empleo en las ciudades latinoamericanas es el achicamiento del aparato gubernamental, por lo que ha disminuido el empleo en la burocracia, sin que las actividades privadas ofrezcan suficientes alternativas. Esto no sólo tiene efectos sobre el mercado de empleo en sí mismo, sino sobre la calidad de los servicios públicos que presta el gobierno de la ciudad. La privatización de los servicios públicos es muy desigual y no admite generalizaciones, pero aun estando pendiente su evaluación, es posible corroborar estos efectos que genera sobre el trabajo en la burocracia, el cual fue en décadas anteriores un importante segmento del mercado de trabajo para las capas medias de la población. Además, junto con el desempleo, el trabajador y su familia pierden el acceso a la seguridad social.

Lo que queda claro es que nuestras ciudades han perdido parte de esa capacidad de asegurar por la vía del empleo formal, estable y asalariado, condiciones de vida razonablemente adecuadas para un segmento importante de la fuerza de trabajo.

En este contexto, otro rasgo del mercado de trabajo urbano es la creciente incorporación del trabajo de la mujer. Moser (1987) estimó que un tercio de los hogares del mundo están encabezados por mujeres. En las áreas urbanas, particularmente en América Latina y África, este porcentaje supera el 50\% de mujeres que deben conseguir alguna actividad remunerada para hacer frente a la superviven- 
cia. Pero en algunos países la creciente incorporación de la mujer al mercado de trabajo es también producto de su mayor nivel de escolaridad. Lo que debe resaltarse es que, independientemente de su calificación, la mano de obra femenina debe aceptar condiciones salariales y de estabilidad desfavorables. La informalidad y la precariedad en el trabajo prevalecen para las mujeres de las clases populares, para quienes el servicio doméstico y el trabajo manual industrial de baja calificación (maquila, vestido, etc.) son las principales actividades. El nuevo modelo económico se caracteriza por la flexibilidad con la que incorpora la fuerza de trabajo, tiempo parcial, subcontratación y desalarización. Se estima que en Bolivia las mujeres representaban, en 1995, "la mitad de los trabajadores del sector informal y sólo una cuarta parte del sector formal" (Borja y Castells, 1997: p. 82). Esto, como bien señalan estos autores, se ha dado a la vez que se mantiene "la función múltiple de la mujer como productora y educadora de niños, gestora del hogar y agente de organización de la vida cotidiana, más importante que nunca en las condiciones del nuevo modelo de urbanización" (Idem, p. 83).

Otro fenómeno notorio en nuestras ciudades es el trabajo infantil. Los niños trabajan en las calles de nuestras ciudades ofreciendo todo tipo de servicios (limpiaparabrisas, vendedores de chicles, cerillo, etc.) y ello permite incrementar el ingreso familiar, a la vez que supone el abandono de las actividades escolares y/o de la capacitación a temprana edad. Su presencia es un síntoma inequívoco de pobreza urbana y exclusión social.

Borja y Castells (1997) ponen especial énfasis en la infantilización de la pobreza urbana diciendo que se trata de una flagrante negación de la noción de progreso en una economía global segregante. Basados en un estudio de UNICEF, estiman que en Brasil entre un 2 y un 16\%, y en México un 10\% de los niños, son "niños de la calle". La realidad es alarmante, y se afirma que en las áreas del mundo en desarrollo los niños urbanos tienen una probabilidad ahora más alta que en 1980 de nacer en la pobreza, de ser prematuros, de morir en su primer año de edad, de nacer de madres que no han recibido asistencia prenatal, y también de trabajar en un ambiente explotador, de drogarse, de practicar la prostitución, de estar expuestos a la violencia callejera (Cfr. Blanc, 1994). Debe decirse que junto con los procesos de transformación de la economía que han implicado la pérdida de empleos como consecuencia de la apertura comercial y la reducción del aparato del Estado, se advierte un incremento de la competitividad internacional que supone el uso poco intensivo de la mano de obra, nuevos empleos concentrados en actividades poco productivas, y demanda de personal con calificaciones específicas (alta educación y calificación). Esto ocasiona marcadas diferencias salariales, así como la polarización, segmentación y marginación para un elevado número de trabajadores. Este deterioro de la situación en el mercado de trabajo se adjudica a la actual etapa de transición, que provoca una fuerte crisis en el mercado de trabajo (CEPAL, 1996: p. 38). 
Además, el mercado laboral urbano está presionado por los jóvenes que anualmente se agregan a la oferta de fuerza de mano de obra y para los cuales no hay suficientes opciones, dadas las restricciones de la demanda y las limitaciones que tiene su calificación para el mundo del trabajo.

Finalmente cabe señalar que ante esta situación no es mucho lo que pueden hacer las autoridades locales de las ciudades, las cuales por lo general no tienen competencias en materia de políticas económicas, entre éstas las de empleo, que son de nivel nacional. Por ello se generan en las ciudades tensiones de difícil resolución, situación bastante diferente a la que prevalece en las ciudades europeas, en las cuales los gobiernos locales han asumido un importante protagonismo económico emprendiendo agresivas políticas de promoción del desarrollo.

\section{La pobreza urbana}

En Europa se habla de una nueva pobreza caracterizada por ser producto de la combinación de factores diferentes a los del pasado reciente, en particular el desempleo prolongado, pero también porque lo que se incrementó notablemente en el viejo continente es la desigualdad social, cuestión ésta que se retomará más adelante. A principios de los noventa se estimaba que 44 millones de personas vivían debajo de la línea de pobreza (Ayuntamiento de Barcelona-Eurociudades, 1991: p. 33), cifra bastante próxima a la que presenta un solo país en América Latina, México, y que supera ampliamente Brasil.

En América Latina la situación es diferente, puesto que la pobreza, según Grynspan (1997), es una situación de privación e impotencia. Privación, porque los individuos no disponen de ingresos ni de activos suficientes para satisfacer sus necesidades materiales más elementales, y ello es producto de la ausencia de educación, destrezas, actitudes, herramientas, oportunidades o activos suficientes para generar ingresos y acumular. Impotencia, porque no poseen ni la organización, ni el acceso al poder político para cambiar la situación por sí solos (p. 94).

Según Londoño, "En 1995, el 35\% de la población de América Latina y el Caribe se encontraba debajo de la línea de pobreza, y el 18,8\% por debajo de la de extrema pobreza. Había 165,6 millones de pobres de los cuales 86,3 eran extremadamente pobres y vivían con un ingreso diario de apenas 1 dólar por persona. La mayor incidencia de la pobreza se concentraba en América Central donde aproximadamente el 60\% de la población es pobre" (1996: p. 4), mientras que Brasil alcanza el 35\% (CEPAL, 1996). En México se estima actualmente que alrededor de la mitad de la población vive en condiciones de pobreza, siendo que una cuarta parte (26 millones) está en situación de pobreza extrema (Maldonado, 1998).

También se estima que de cada 10 hogares urbanos 7 son pobres, debido principalmente a los bajos ingresos laborales, 2 a consecuencia del desempleo de 
alguno de sus miembros y 1 casi exclusivamente por estar integrado por un elevado número de menores (CEPAL, 1997: pp. I-33).

Ahora bien, si durante mucho tiempo se consideró que la pobreza era una situación generada por la incapacidad o la precaria forma de los individuos de insertarse en el sistema productivo, actualmente existen evidencias de que en el mercado de trabajo asalariado existe un elevado número de familias trabajadoras que viven en situación de pobreza. A ello se agregan la precariedad y las dificultades que presentan estos trabajadores en otras dimensiones de la vida social (organizativas, culturales, de justicia, etc.), que refuerzan la condición de pobre y expresan los obstáculos y el carácter integral que deben enfrentar las políticas sociales que pretendan combatirla.

Los asalariados que registran altos niveles de pobreza están fuera del mercado vinculado a las actividades más modernas y se insertan en microempresas de baja productividad ${ }^{7}$. Estos viven en condiciones de precariedad similares a las de los trabajadores de los servicios domésticos o por cuenta propia, de baja calificación ${ }^{8}$.

También existe un número considerable de pobres entre los empleados públicos y asalariados de empresas privadas medianas y grandes. CEPAL estima que en más de la mitad de los países de América Latina, entre el 30 y el 50\% de los asalariados del sector privado viven en hogares pobres?

Los bajos ingresos de los empleados públicos sin duda constituyen un obstáculo al proceso de reforma y modernización del Estado. En Bolivia, Honduras y Venezuela, entre 30 y $40 \%$ de los funcionarios públicos se encontraban bajo el umbral de pobreza; en Colombia y Paraguay, cerca de $15 \%$, y en Costa Rica y Panamá el 5\%. En Uruguay, en cambio, sólo $2 \%$ de ellos pertenecían a hogares pobres. Es decir, una alta proporción del total de los ocupados pobres está constituida por asalariados del sector formal, lo que no les asegura situarse por encima del umbral de la pobreza ${ }^{10}$.

Otra cuestión vinculada al empleo que tiene importantes efectos urbanos es la disminución del salario real de los trabajadores, la cual se dio particularmente en la década de los ' 80 . En algunos países ha mejorado en esta década, aunque se trate de una situación muy heterogénea.

Se estima que los niveles salariales en 13 de los 17 países latinoamericanos considerados en 1997 eran inferiores a los de 1980, porque aunque hubo una recuperación salarial en algunos países, este proceso se interrumpió en 1996. Al mismo tiempo, los trabajadores informales suelen trabajar un mayor número de horas y perciben una remuneración media que alcanza a la mitad de la que perciben los obreros y empleados en establecimientos modernos (CEPAL, 1997: pp. I-15). 
En consecuencia, el deterioro salarial tiene diferentes consecuencias: i) disminuye la capacidad de adquisición de bienes básicos de las familias, entre éstos los que demandan la educación, la salud, la cultura, ii) incrementa la demanda de bienes al sector público, al mismo tiempo que el gobierno tiende a disminuir el gasto social como parte de una política generalizada de reforma del estado, lo que a su vez provoca menor calidad por la reducción de personal calificado y el incremento de la demanda.

Estas situaciones obligan a la familia a buscar diferentes estrategias de supervivencia y a incorporar un mayor número de miembros al mercado de trabajo. Ello incide sobre los jóvenes cuya permanencia y dedicación en el sistema educativo disminuye, las mujeres que aceptan trabajos de muy baja productividad en condiciones de precariedad, y los niños que son expuestos a trabajar en las calles de la ciudad. El resultado es que numerosas familias están excluidas de acceder a bienes y servicios básicos. A ello se agrega que muy probablemente están excluidas de acceder a los mecanismos que organizan la vida social (ej. la justicia), es decir, que enfrentan situaciones de exclusión social .

\section{La exclusión social}

La noción de exclusión social aparece en Europa cuando se acepta que existe un desempleo de larga duración, que un número considerable de personas no tienen vivienda, que existen nuevas formas de pobreza, que el estado benefactor se reestructura ante la crisis fiscal, y que los sistemas de la seguridad social ceden paso a la solidaridad para atender la cuestión social.

Para Rosanvallon (1995) la cuestión social se desplazó: "se pasó de un análisis global del sistema (en términos de explotación, repartición, etc.) a un enfoque centrado en el segmento más vulnerable de la población". "La lucha contra la exclusión polarizó toda la atención, movilizó las energías, ordenó la compasión" (1995: p. 83). El riesgo, para este autor, es hacer de la selectividad un principio filosófico que puede llevar a reducir el estado de providencia a un sistema de asistencia a los más pobres (versión de derecha de la ideología de la selectividad) o a restablecer la mitología de que los ricos pueden pagarlo todo (que sería la versión de la izquierda) (1995: p. 95).

Sin duda esta descripción podría utilizarse para describir la realidad latinoamericana, donde en lugar de selectividad se habla de focalización, criterio que ha permitido fundamentar una restringida responsabilidad gubernamental en la cuestión social.

En Europa se percibe una tendencia a disociar lo económico de lo social, y se considera que las sociedades son lo suficientemente ricas como para hacerse cargo de la exclusión. Pero ante las propuestas de asalariar la discapacidad y el 
ingreso de subsistencia, Rosanvallon propone "la inserción por el trabajo", la cual debe seguir siendo la piedra angular de toda lucha contra la exclusión. Es decir, para este autor el principal desafío que enfrenta la cuestión social continúa siendo el garantizar el derecho al trabajo.

En América Latina la situación es bastante diferente. La exclusión social no es un fenómeno de las últimas décadas: ha sido siempre la situación que han debido aceptar grandes mayorías, aunque pudo haberse amplificado a partir de la aplicación de políticas neoliberales. En el medio urbano, la marginalidad social sustentó en los ' 60 varios desarrollos teóricos sobre las causas y las dificultades de la sociedad latinoamericana para crear mecanismos efectivos de integración social. El derecho al trabajo, aunque reconocido en las leyes máximas de las repúblicas, nunca estuvo garantizado para el conjunto de la ciudadanía, y esto ha sido similar para otros bienes básicos.

La masividad y las variadas formas que asume la exclusión social son fenómenos muy conocidos por los sectores populares urbanos. Pero lo que interesa señalar es que, a diferencia de la noción de pobreza, la exclusión social alude en América Latina a un "fenómeno producido por la interacción de una pluralidad de procesos (o factores) elementales que afectan a los individuos y a los grupos humanos, impidiéndoles acceder a un nivel de calidad de vida decente, y/o participar plenamente, según sus propias capacidades, en los procesos de desarrollo" (Quinti, 1997: p. 74). Por ello, hablar de exclusión "adquiere sentido en el contexto de la globalización que segmenta y polariza el todo social, al incorporar a algunos sectores de la población en la economía, la cultura, la tecnología internacionalizada y excluir a grandes mayorías para acceder o ejercer una o todas estas dimensiones" (Idem).

Los campos que permiten operacionalizar el concepto de exclusión social son, entre otros: las dificultades de acceso al trabajo, al crédito, a los servicios sociales, a la instrucción; el analfabetismo; la pobreza; el aislamiento territorial; la discriminación por género; la discriminación política; la carencia de viviendas; la discriminación étnico-lingüística. Todos ellos son considerados "factores de riesgo social".

Pero lo fundamental es que la pobreza extrema o el analfabetismo pueden por sí mismos ser tan graves que comporten ellos solos formas de exclusión: exclusión social directa (Quinti: 1997: p. 74).

Ante esto, cualquier política sectorial será sumamente débil si no se integra a una acción social gubernamental que enfrente no sólo la pobreza sino también la exclusión social. Y esto señala el amplio campo de actuación de las políticas sociales urbanas, puesto que desde las mismas pueden disminuirse algunos de los efectos más desfavorables de la pobreza y de la exclusión social. 


\section{Las dimensiones de la desigualdad}

A la pobreza y exclusión se agregan las marcadas desigualdades sociales que caracterizan a la sociedad de los noventa, cuyos efectos son particularmente graves en las ciudades. Estas se advierten en la marcada segregación urbana e inequidad que prevalecen en el acceso a bienes y servicios sociales.

La situación social generada por la aplicación del modelo neoliberal ha llevado a que Fitoussi y Rosavallon (1997), refiriéndose al mundo desarrollado, hablen de una "nueva era de las desigualdades", ya que por un lado persisten las llamadas desigualdades tradicionales o estructurales producto de la jerarquía de ingresos entre categorías sociales (obreros, ejecutivos, empleados, etc.), las cuales se ampliaron y se modificaron en relación con la percepción que tiene la sociedad de las mismas. Por el otro, aparecen nuevas desigualdades "que proceden de la recalificación de diferencias dentro de categorías a las que antes se juzgaban homogéneas", es decir, son desigualdades "intracategoriales" (pp.73-4). La dimensión plural de la desigualdad, observada por estos autores en Francia, los lleva a confeccionar un "repertorio de desigualdades" que se fundan en: i) la desaparición del modelo clásico de trabajo asalariado, bajo el efecto de la desocupación masiva que no afecta a todos los individuos al mismo tiempo y no depende sólo de las capacidades individuales, sino de la forma como se relacionan estos con la coyuntura; ii) las mujeres que se han integrado a la economía pero aceptando numerosas diferencias con los hombres en materia salarial, de precarización del trabajo, y entre las que se advierten mayores índices de desempleo; iii) las desigualdades geográficas entre regiones de un país o áreas en una ciudad que expresan territorialmente las desigualdades sociales; iv) las prestaciones sociales que están condicionadas a los recursos del beneficiario potencial; v) las facilidades u obstáculos para acceder al sistema financiero; vi) la situación diferencial que se advierte en la vida cotidiana frente a la salud, la vivienda, a los equipamientos públicos, al transporte.

Todos estos procesos, que suelen ser acumulativos, estructuran representaciones contrastantes de la sociedad y de su territorio. Justamente, disminuir las desigualdades mencionadas en último término debe ser uno de los objetivos explícitos de las políticas sociales urbanas.

Puede decirse que la desigualdad social ha sido un componente constitutivo de la sociedad y la ciudad latinoamericana, pero la misma se ha incrementado tanto, que se estima que en la actualidad es mayor a la imperante en los años '60 o principios de los '70 (CEPAL, 1996: p. 34). Pero, ¿cuáles son los principales tipos de desigualdad que existen?

En primer lugar debe mencionarse que en nuestros países persisten grandes desigualdades en el acceso a bienes y servicios entre el medio rural y urbano, ya que es en las ciudades donde, a pesar de todo, los trabajadores pueden acceder a 
éstos con mayor facilidad ${ }^{11}$. Frente a ello, la Red sobre Políticas Sociales Urbanas propone acertadamente una política social integradora.

Por otra parte, tanto en las zonas urbanas como en las rurales, las desigualdades del ingreso fuertemente arraigadas obedecen a marcadas diferencias en el nivel de educación y a la segmentación de los mercados de trabajo y de crédito, así como a profundas desigualdades en el acceso a la tierra (CEPAL, 1996: p. 34).

Pero la principal desigualdad sigue siendo de tipo estructural y corresponde a las diferencias de ingreso entre los trabajadores, las cuales tienden a incrementarse notablemente entre categorías laborales. Se estima que "la distancia entre los ingresos de profesionales y técnicos y los de los sectores de baja productividad aumentó entre un 40 y un 60\%, entre 1990 y 1994. La manutención o aumento de la dispersión de los ingresos laborales, como reflejo de las marcadas diferencias de productividad entre empresas y sectores, es un factor importante para comprender la rigidez en el ingreso que ha acompañado al crecimiento económico reciente..." (CEPAL, 1997: pp. I.15-16).

La mayor desigualdad se observa en Honduras y Perú y la menor en Uruguay y Barbados, y se llega a caracterizar a la región por el "exceso de desigualdad" que presenta, ya que 15 de 17 países poseen niveles mayores de desigualdad a lo esperado, de acuerdo con su nivel de desarrollo.

Las grandes ciudades de Brasil, México, Perú, Colombia y Argentina expresan espacialmente y con mayor crudeza la marcada desigualdad que existe en la sociedad. Un estudio realizado en Sao Paulo en 1993 ponía en evidencia la existencia de desigualdades extremas entre los cuatro grupos en los que se repartió la población estudiada. Así, la tasa de desempleo de los más pobres era casi cinco veces más alta que la de los más acomodados, y en el grupo de los más pobres un $39 \%$ de las familias estaba por debajo del nivel de pobreza, dependiendo en un $30 \%$ de los ingresos del trabajo de los niños. La tasa de analfabetismo era 7 veces más alta en el grupo de mejores ingresos. Más de la mitad de los 'cabeza de familia'no había terminado la enseñanza primaria, y un $87 \%$ de los miembros de la familia mayores de 7 años no habían cursado o terminado la enseñanza secundaria. En cuanto a la vivienda, más de un $37 \%$ de las familias de Sao Paulo vivía en condiciones por debajo de los estándares habitacionales, mientras que el $13 \%$ lo hacía en condiciones "muy satisfactorias". En conjunto, un 11.3 por ciento de las familias del área metropolitana se encontraba en condición de miseria extrema, con ingresos de tan sólo un $26 \%$ de la media familiar. Numerosos niños vivían frecuentemente en chabolas (ilegalmente en un 15\%), con mayor proporción de negros o mulatos (un $42 \%$ de las familias en estado de miseria), y mayor incidencia de inmigración reciente a São Paulo. Según ese estudio, el alto dinamismo económico de São Paulo en los últimos años ha dado como resultado una desigualdad social creciente para sus habitantes (Borja y Castells, 1997: p. 73) ${ }^{12}$. 
De igual forma, las desigualdades se expresan en el origen étnico. Los indígenas en Lima, La Paz o Ciudad de México deben superar diferentes obstáculos para hacer efectivos los principios de igualdad y de igualdad de oportunidades en el acceso a bienes y servicios básicos consagrados en las leyes.

Juan Luis Londoño afirma que "el factor aislado más importante que contribuye a la persistencia de la desigualdad y al aumento de la pobreza ha sido la falta de educación adecuada para las nuevas generaciones. Por cierto, se han combinado varios factores - el crecimiento económico y la transformación estructural de la economía, la convergencia del ingreso per cápita regional y las decrecientes tasas de rentabilidad de la educación- para disminuir la desigualdad de la región. Sin embargo, la lenta expansión de la formación del capital humano ha neutralizado dichos factores y la región muestra un nivel estadísticamente estacionario de gran desigualdad. El trabajador latinoamericano medio tiene dos años menos de instrucción que lo que podría esperarse según el nivel de desarrollo económico de la región" (1996: p. 1).

Frente a esto, Coraggio sugiere ponderar este factor al afirmar que: "Se suele mencionar a la educación como una política social principal, en tanto haría más equitativa la distribución del capital humano (conocimientos, capacidades, destrezas, etc.) con el que las personas competirán por los puestos de trabajo disponibles. Así por el lado de la oferta de trabajo, la principal vía de acción resultante consiste en intervenciones en el terreno de la capacitación (reciclaje) y educación (habilidades básicas para la flexibilización), en lo posible asociada a demandantes concretos, o en programas de apoyo para facilitar las adecuaciones en las tasas de participación femenina (centros infantiles). En todo caso, ésta es claramente una política sectorial y, por lo tanto, ineficaz e ineficiente, pues la educación por sí sola no contribuye a mejorar la condición competitiva de los trabajadores en su conjunto frente al capital" (1998 [c]: p. 5).

Un claro ejemplo de cómo se superponen las dimensiones de la desigualdad en relación de género y de acceso a la educación lo ofrece la ciudad de México. En el territorio del Distrito Federal, en 1990, el 73\% de los analfabetos eran mujeres y por cada 100 hombres sin primaria completa había 120 mujeres (Ziccardi, 1998). Frente a esto, el nuevo gobierno de la ciudad ha puesto en marcha políticas sociales donde se introduce una perspectiva de género explícita, de manera de actuar sobre esta dimensión de la desigualdad social para modificarla (Idem).

Pero lo importante es enfatizar la complejidad que encierra cualquier política social que intente atacar la desigualdad, puesto que debe partir de principios de integralidad, de una nueva e innovadora institucionalidad, y de relaciones entre lo público y lo privado cualitativamente diferentes. 


\section{Los problemas de la ciudad actual}

\section{La urbanización de la pobreza en América Latina}

En las sociedades latinoamericanas la pobreza es hoy la principal cuestión social, tanto en el medio rural como en las ciudades. A diferencia de épocas anteriores en las que la pobreza se localizaba predominantemente en el campo, en las últimas décadas ha crecido notablemente en el medio urbano. Esto está vinculado al mayor crecimiento de la población urbana en relación con la rural, y a la incapacidad del sistema productivo para ampliar las opciones de empleo estable y bien remunerado, lo cual genera tanto desempleo como las diferentes modalidades de empleo precario e informal que ya se han expuesto.

En las ciudades latinoamericanas, algunas décadas atrás la pobreza se localizaba espacialmente en enclaves urbanos: formas precarias y deterioradas de habitación colectiva denominadas de manera diferente en los países de la región (conventillos, cortijos, inquilinatos, bodeville) y asentamientos populares autoconstruidos (favelas, villas miseria, colonias populares, campamentos), las cuales compartían, no obstante sus diferencias, rasgos comunes. Estas formas de habitación popular eran expresiones espaciales de la llamada marginalidad, categoría creada en la época para diferenciar a estos sectores sociales del tradicional ejército industrial de reserva, puesto que esta masa marginal independientemente de sus atributos y capacidades, era un excedente de la fuerza de trabajo que no lograba insertarse en el sistema productivo. Dado que su presencia en el medio urbano encerraba cierto grado de conflictividad social, espacial y política, esta población pasó a ser disputada por fuerzas políticas que enarbolaban proyectos de defensa y reivindicación de los intereses populares, en el sentido más amplio del término.

Los llamados movimientos sociales urbanos que tenían en su base este tipo de reivindicaciones pasaron a ser interlocutores de las políticas urbanas y objeto de interés del análisis social. Pero la represión política y los gobiernos militares y/o autoritarios que se implantaron en América Latina en los años '70 tendieron a su desintegración. A pesar de ello, los mismos fueron un embrión político importante cuando se reestructuraron los sistemas políticos y se dio una apertura democrática, ya que fueron proveedores de líderes políticos y de experiencias de organización social.

La cuestión social fue caracterizada entonces como "una cuestión de policía", y lo fue por varias décadas. Recién a mediados de los ochenta el retorno gradual a la democracia en los países latinoamericanos, particularmente del cono sur, llevó a que las políticas sociales volvieran a ocupar un lugar en la agenda gubernamental, pero muy diferente al de décadas anteriores. Despojadas la mayoría de ellas (salvo la educación) de sus pretensiones universalizantes, las mismas se orientaron a compensar, por la vía de la focalización, los altos costos que impli- 
caron los ajustes de las economías. Ello supuso la reestructuración (privatización) de la seguridad social y la descentralización de los recursos y las competencias relacionadas con la cuestión social desde el gobierno central hacia los locales.

La pregunta es cómo y con qué criterios se seleccionan los más pobres entre los pobres ante un aumento generalizado de la pobreza. Así, si se compara con los niveles de 1980, sólo cuatro países tienen un nivel menor de pobreza (Brasil, Chile, Panamá y Uruguay), en tanto otros cuatro registran mayores niveles que hace 16 años (Argentina, México, Venezuela, y Honduras). Por ello, el número de pobres de la región sumando pobres e indigentes alcanzaba en 1994, según CEPAL, un total de 209,3 millones, de los cuales 135 millones de pobres ${ }^{13}$ viven en zonas urbanas (CEPAL, 1997: p. I-31).

En América Latina, entre 1980 y 1990, el número de pobres que viven en áreas urbanas, es más del doble. En el último quinquenio se incrementó en alrededor de un $10 \%$ más, y un ritmo similar tuvo el crecimiento del número de indigentes. También es importante considerar al formular políticas sociales urbanas que la población indigente, que creció en 6,4 millones entre 1990 y 1994, se concentró casi exclusivamente en el medio urbano (CEPAL, 1997: pp. I-30-31). Por ello, esta urbanización de la pobreza es una de las características más importantes de este fenómeno en América Latina en los últimos decenios.

Vale la pena concluir este apartado considerando que "el 1,8\% del crecimiento económico de la región y el rápido traslado de la fuerza de trabajo a las ciudades ha producido una disminución de la incidencia de la pobreza en América Latina, pero no ha reducido el número absoluto de pobres. Hoy en día, el número absoluto de pobres es del doble de lo que era 40 años atrás" (Londoño, 1996: p. 8). Por ello es claro que el crecimiento económico es una condición necesaria pero no suficiente para reducir la pobreza. Deben revisarse el modelo y las políticas económicas adoptadas para que las políticas sociales urbanas representen el papel que les corresponde, que, como ya se dijo, es el de asegurar la equidad y la promoción de los derechos básicos de la ciudadanía.

\section{La segmentación social y la segregación urbana}

Una de las particularidades que poseen las ciudades de los '90 son las contrastantes condiciones de vida que ofrecen a sus habitantes. Las ciudades se caracterizan hoy por ser divididas, fragmentadas, segmentadas, situación que suele atribuirse en el caso de las ciudades de los países desarrollados a la adopción de los modelos económicos neoliberales en materia de política económica, y a la reestructuración de las políticas sociales que desencadenó la crisis del estado de bienestar (Fainstein et. al. 1992: Jacobs, 1992). 
Sin embargo, éstos han sido los rasgos de las ciudades latinoamericanas desde su propia conformación, que ciertamente se han profundizado por la dinámica de una economía urbana que posee un segmento integrado a la economía internacional, otro que se opera en el mercado interno, y un tercero comprendido por una amplia variedad de actividades que forman parte del sector informal.

Por ello se han desarrollado espacios urbanos de riqueza y opulencia, verdaderos enclaves de riqueza, y han proliferado los mega-centros comerciales que ofrecen productos suntuarios, así como Mc Donald's y restaurantes que son cadenas internacionales, los cuales contribuyen a homogeneizar el paisaje urbano de estas zonas, imprimiéndoles los rasgos que poseen todas las grandes ciudades del mundo actualmente. Pero confrontando con esa modernidad, las ciudades en este fin de siglo muestran un agravamiento de la segregación urbana. Hace treinta años atrás, las grandes ciudades se expandían a través de asentamientos populares auto-construidos que albergaban la masiva migración rural. Estos fueron producto de la construcción precaria de viviendas y de un lento y desgastante proceso de lucha y organización para obtener los servicios básicos. Los regímenes militares impusieron políticas urbanas de "erradicación" de la pobreza, y los más ambiciosos programas para eliminar la pobreza en el medio urbano de la época se pusieron en marcha en ciudades como Buenos Aires y Río de Janeiro (Ziccardi, 1983). Las dictaduras de la década siguiente finalmente expulsaron a un considerable número de habitantes de estos barrios populares hacia la periferia lejana. Hoy, Buenos Aires es una ciudad en la cual, por lo menos en el perímetro de su Capital Federal, es difícil para un observador externo percibir dónde se localiza la pobreza. En los morros de Río de Janeiro, en cambio, la pobreza de la favela carioca es inocultable.

En países donde el pacto político se basó en la inclusión de los sectores populares, estos asentamientos populares fueron tolerados y/o promovidos, como es el caso de México. Pero el fracaso de la mayoría de estas experiencias autoritarias contribuyó también a proponer políticas de mejoramiento y dotación de servicios básicos basadas en que los pobladores aportaran mano de obra gratuita, lo cual contó en algunos casos con el apoyo de los organismos internacionales (ej.: las ciudades de Colombia o Perú).

Sin embargo, estos barrios no están integrados ni social ni territorialmente de manera plena a la estructura urbana de la ciudad central. Además crecieron en el número de habitantes y por tanto en sus índices de hacinamiento, aunque sus luchas lograron la introducción de los servicios más elementales (agua, drenaje, transporte público). Su presencia contrasta cada vez más con la ciudad de la globalización, la de los corredores del capital financiero y comercial que son extremadamente parecidos en cualquier gran ciudad del mundo.

Así, parece ser claro que los sectores populares son los que más apoyo requieren y a la vez los que necesitan dedicar más tiempo a actividades económi- 
cas que garanticen su supervivencia y la de su familia. Y, sin embargo, es a ellos a los que se les exige que contribuyan con su trabajo y que participen social y políticamente. Mientras que las capas medias y altas de la población ejercen sus derechos ciudadanos y el gobierno se encarga de introducir y mantener en sus colonias la infraestructura (calles, instalaciones de agua potable y drenaje) y los equipamientos (escuelas, centros de salud), las clases populares, para tener acceso a los mismos, deben aportar trabajo comunitario aun cuando sus viviendas estén regularizadas y paguen impuestos (ej. predial) y derechos por servicios (agua). Más allá del valor social que pueda darse al trabajo comunitario, éste es uno de los procesos en los que se advierte más claramente la inequitativa distribución de bienes y servicios urbanos que prevalece en nuestras ciudades.

Además de este tipo masivo de asentamiento popular, las ciudades latinoamericanas conservan en sus zonas centrales viviendas en renta, las que representan una alternativa de habitación popular cada vez menos importante ya que presentan severos niveles de deterioro. Las mismas son otra forma de segregación urbana, y sus habitantes han protagonizado importantes luchas, como fue el caso del movimiento de damnificados por los sismos de 1985 en la ciudad de México ${ }^{14}$.

\section{La inequidad en el acceso a los servicios y equipamientos urbanos}

Ahora bien, las ciudades latinoamericanas, de acuerdo a su escala y al grado de desarrollo del país, se han caracterizado por ofrecer excelentes condiciones de vida para los sectores de más altos ingresos, niveles aceptables de confort para las capas medias, y situaciones de precariedad, deterioro y miseria para grandes contingentes que forman parte de los sectores populares. Hoy, precisamente, esta diferenciación se ha acrecentado y el espacio expresa la polarización social que existe en estos países y en sus ciudades, lo cual contribuye a generar un clima propicio para el desarrollo de la inseguridad y la delincuencia hasta niveles nunca antes alcanzados.

Lo limitado de las remuneraciones de las familias trabajadoras impide que ellos mismos puedan disponer de recursos para invertir en sus viviendas y en sus equipamientos. Es decir, el masivo proceso de autoconstrucción del hábitat popular que protagonizaron las clases populares en décadas anteriores encuentra severas restricciones económicas para desarrollarse, a la vez que existe un mayor control de parte de las autoridades para impedir que se creen nuevos asentamientos, lo que hace que se incremente el hacinamiento en los existentes.

Lo limitado del presupuesto de los gobiernos locales, en gran medida destinado a gastos de administración de la ciudad consolidada, impide la formulación de políticas tendientes a construir obras públicas básicas, a lo que se agrega en algunos casos la imposibilidad de hacerlo por lo inapropiado del terreno en donde se han localizado originalmente estos barrios populares. 
Se puede afirmar que uno de los rasgos más distintivos de las ciudades latinoamericanas, a diferencia de las europeas, es el grave déficit de servicios y equipamientos básicos que presentan los barrios populares, los cuales son en algunos casos verdaderas ciudades de pobres en el interior de la gran ciudad. Esto es una clara expresión espacial de una ciudadanía restringida.

Sin duda, en las ciudades capitales, las cuales muchas veces son ciudades primadas (Buenos Aires, Montevideo, Santiago), los ciudadanos pueden acceder a niveles adecuados de servicios colectivos básicos en materia de educación, salud, recreación. Sin embargo, en relación con los servicios habitacionales (agua, drenaje, luz, calles, etc.) es donde se advierten graves carencias. También es común que los barrios populares se localicen en la periferia y que el transporte colectivo sea deficitario, costoso, e implique la pérdida de muchas horas de traslado.

Así, una política social urbana que pretenda modificar esta situación debe partir de evaluar con precisión: 1) la magnitud y las características de los bienes urbanos colectivos básicos que posee cada ciudad, 2) la capacidad económica y los recursos humanos con los que cuenta la población para mejorar su propio hábitat, 3) la capacidad organizativa de la ciudadanía, y 4) las modalidades que asumen las relaciones intergubernamentales entre el nivel central y el nivel local encargadas de atender la cuestión social y urbana.

\section{La inseguridad y violencia urbana}

La violencia e inseguridad que prevalecen en todas las ciudades del mundo son un efecto de estos contrastes sociales y territoriales y de las marcadas desigualdades existentes. Sin embargo, lo particular de América Latina es que esto no puede relacionarse exclusivamente con la incapacidad de controlar el delito por parte de los cuerpos policiales, lo cual existe, sino también con las políticas sociales urbanas que deben articularse entre sí para transformar la grave situación social que lo promueve. En un contexto caracterizado por elevados índices de pobreza, desigualdad social y falta de justicia (Neira, 1996), están dadas las condiciones para que la delincuencia prolifere. $\mathrm{Y}$ es evidente que se ha incrementado en la última década a niveles francamente alarmantes, como es el caso de la ciudad de México o São Paulo, Río de Janeiro o Cali y Bogotá, donde se registran altísimos índices de delitos de venta y consumo de drogas.

Se estima que en América Latina, entre 1980 y 1991, la tasa de homicidios subió de 12.8 a 21.4 por 100 mil habitantes. Ese aumento se dio prácticamente en todos los países y sub-regiones, y las ciudades son el principal escenario. Por ejemplo, Cali, que es uno de los centros mundiales del tráfico ilegal de cocaína, registró un brusco aumento de la tasa de homicidios, que pasaron de 23 por 100 mil habitantes en 1983, a más de 100 por 100 mil habitantes a comienzos de 1990. Aunque muchos de los homicidios podrían atribuirse directamente al tráfi- 
co de drogas, gran parte parecía ser resultado de la propagación de una cultura de violencia. En 1992 se impulsó un Programa para el Fomento de la Seguridad y de la Paz, "partiendo del principio de que la prevención debía prevalecer sobre la represión, y tras un análisis exhaustivo de las pautas de la criminalidad, el programa se puso en acción para combatir la delincuencia en diferentes frentes. En 1995, después de siete años consecutivos de aumento (hasta llegar a un máximo de 120 homicidios por 100 mil habitantes), la tasa de homicidios de Cali finalmente comenzó a disminuir" (Banco Mundial, 1997; Cit. Castells y Borja, 1997: pp. 17 y 20).

Pero estos ejemplos puntuales están lejos de generalizarse, y mientras tanto la ciudadanía se ve cotidianamente amenazada, debiendo replegarse cada vez más en su individualidad, y perdiendo la convivencia urbana en el barrio y en la ciudad el valor que encerraba en los procesos de la socialización e integración social. Por su parte, los gobiernos nacional y local, en lugar de destinar mayores recursos a las políticas sociales, deben destinarlos a la seguridad pública, que se transforma en la primera y principal demanda de la ciudadanía.

\section{La vulnerabilidad social y espacial}

Ha quedado demostrado que la magnitud de la pobreza en algunos países latinoamericanos es tal, que el crecimiento económico y la inversión sostenidos durante varias décadas no alcanzarían para revertir la situación de privación y vulnerabilidad en que se encuentran ciertos grupos sociales. Por ello, los gobiernos difícilmente podrán disminuir su presencia en relación con la atención de la cuestión social y/o traspasar cada vez más las responsabilidades a la sociedad.

El discurso gubernamental debe ajustarse a las restricciones que presenta el gasto social. Por ello, ante la magnitud de las demandas apela a una noción de vulnerabilidad que le permite ajustar aun más los criterios de focalización que orientan las políticas sociales de atención a la pobreza. Es algo así como la focalización de la focalización, elegir los más pobres entre los pobres para atenderlos prioritariamente.

Rosalía Cortés (1996) propone un concepto bastante amplio de vulnerabilidad social que dice: "Diferentes grupos y sectores de la sociedad están sometidos a carencias y procesos dinámicos de inhabilitación que los colocan en situaciones que atentan contra la capacidad de resolver los problemas que plantea la subsistencia y el logro social de una calidad de vida satisfactoria. En lo fundamental, éstas dependen de la existencia y de la posibilidad de acceder a fuentes y derechos básicos de bienestar, trabajo remunerado y estable, conocimientos y habilidades, tiempo libre, seguridad y provisión de servicios sociales, patrimonio económico, ciudadanía política, integración e identidad ética y cultural" (Cit. Coraggio, 1998: p. 7). 
La vulnerabilidad social refiere entonces a aquellos grupos que en la sociedad están más expuestos a privaciones: las mujeres, los niños, los ancianos, los indígenas, que se identifican como grupos vulnerables a los que hay que atender prioritariamente. Tal es el caso de personas que en razón de su edad, el ciclo económico u otras circunstancias, quedan marginadas de la economía salarial en algún momento de su vida, y para quienes se diseñan programas de apoyo económico y de asistencia social.

Además, se considera que existen activos materiales que reducen la vulnerabilidad y la inseguridad (como la vivienda), activos sociales (relaciones con otras personas de confianza), activos políticos (alianzas), ambientales (recursos naturales) y de infraestructura (carreteras, transporte). Estas posiciones son asumidas por varios gobiernos, entre ellos el de la ciudad de México, el cual actualmente está desarrollando políticas sociales que identifican a grupos de alta vulnerabilidad que se incluyen en un esquema asistencialista y compensatorio: los llamados niños de la calle, las víctimas de la violencia intra-familiar, la población con adicciones, las víctimas del VIH-SIDA, los sexoservidores (as), los indigentes, y los familiares de población recluida.

Pero debe resaltarse la vulnerabilidad que ha quedado al descubierto dramáticamente en varias ciudades latinoamericanas ante los desastres naturales. En Centroamérica, México y Argentina, los huracanes, inundaciones y sismos afectaron principalmente a la población más pobre. En los últimos años se vivieron tragedias. Es difícil adjudicar, como se pretende hacerlo, que es la ausencia de una cultura ante los desastres naturales lo que ocasiona esta situación. Las muertes y la devastación de zonas enteras son producto de la pobreza en la que viven sus habitantes, así como de la falta de inversión pública en la creación de infraestructuras adecuadas.

\section{La ciudad multicultural}

Investigaciones recientes del campo de la antropología urbana han aportado mayores conocimientos sobre el uso del espacio urbano por sociedades cada vez más complejas, en las que se advierte una fuerte presencia de los diversos componentes de origen étnico y cultural. Etnicidad y raza deben ser incluidas cuando se analizan las desigualdades sociales existentes, ya que son atributos que conllevan a la exclusión.

En las ciudades europeas, la fuerza de trabajo de origen no europeo (dos tercios de los extranjeros en Francia y tres cuartas partes en Alemania y Holanda) sufre discriminación y xenofobia. En sus barrios, que poseen las características de los típicos ghettos, sus habitantes sobreviven gracias a la protección colectiva, la ayuda mutua y la afirmación de su identidad de origen. 
Borja y Castells ofrecen una documentada descripción de esta situación al decir: "parece haberse establecido la tendencia a la segregación de las minorías étnicas en todas las ciudades y, en particular, en las ciudades del mundo más desarrollado. Así, conforme las sociedades europeas reciben nuevos grupos de inmigrantes y ven crecer sus minorías étnicas a partir de los grupos establecidos en las tres últimas décadas, se acentúa el patrón de segregación étnica urbana. Según el Consejo de Europa (1993) en el Reino Unido, aunque Londres sólo representa $4,7 \%$ de la población, concentra el $42 \%$ de la población de las minorías étnicas. Dichas minorías, concentradas particularmente en algunos distritos, se caracterizan por un menor nivel de educación, mayor tasa de paro y una tasa de actividad económica de tan sólo 58\%, comparada con el 80\% de los blancos (Jones, 1993). En el distrito londinense de Wandsworth, con unos 260.000 habitantes, se hablan unas 150 lenguas diferentes: a esa diversidad étnico-cultural se une el dudoso privilegio de ser uno de los distritos ingleses con más alto índice de carencias sociales. En Goteborg (Suecia), el 16\% de la población es de origen extranjero y tiene concentrada su residencia en el nordeste de la ciudad y en las islas de Hisingen. Zúrich, que ha visto aumentar su población de extranjeros (sobre todo turcos y yugoslavos) del 18\% en 1980 al 25\% en 1990, concentra un 44\% de esta población en las zonas industriales de la periferia urbana. En Holanda, los extranjeros son tan sólo un 5\% de la población total, pero en Amsterdam, Rotterdam, La Haya y Utrecht dicha proporción oscila entre el $15 \%$ y el $20 \%$, y en los barrios antiguos de dichas ciudades sube hasta el 50\%. En Bélgica la proporción de extranjeros es del 9\%, pero en la ciudad de Anderlecht alcanza el 26\% y en el barrio de La Rosee, el más deteriorado, los extranjeros representan $76 \%$ de sus 2.300 habitantes" (1997: pp. 25-126).

Por ello estos autores advierten sobre el peligro de que las ciudades europeas estén siguiendo, en buena medida, el camino de segregación urbana de las minorías étnicas característico de las metrópolis norteamericanas, aunque la forma espacial de la segregación urbana es diversa en Europa. Como sostienen Borja y Castells (1997), la ciudad segregada es la ciudad de la ruptura de la solidaridad social y, eventualmente, del imperio de la violencia urbana.

En las ciudades latinoamericanas la situación es bastante diferente, ya que no se trata de población extranjera, la que es discriminada y segregada, sino que son ciudadanos nacidos en éstas.

Alba Zaluar (1994), refiriéndose a Brasil, afirma que los mulatos ocupan los niveles más bajos de la escala social, pero la segregación social y urbana es menor que en las ciudades europeas o estadounidenses aunque habiten favelas. La razón es que ese país recibió oleadas migratorias que supusieron diferentes razas y religiones pero, al contrario de lo que ocurre en otros multirraciales y étnicos, nunca hubo guerras religiosas de larga duración y sólo se puede citar el movimiento milenarista del siglo pasado. 
Lo que puede decirse de las ciudades brasileñas es que, aunque exista discriminación racial, ésta no es fácilmente perceptible. Lo que se puede visualizar rápidamente, al igual que en otras ciudades latinoamericanas, es que los atributos étnicos y raciales tienden a coincidir con la pobreza y la segregación urbana en las periferias precarias y deterioradas.

\section{La cuestión social y los actores urbanos}

La construcción de ciudadanía (Ziccardi, 1998: Cap. I).

Ciudad y ciudadanía son vocablos que no suelen asociarse a pesar de su raíz común. Pero sin duda, la ciudad es el espacio donde se afincaron y se expandieron a lo largo de la historia los derechos ciudadanos. En el Congreso Europeo de Bienestar Social (1991) se afirmó que "La ciudadanía europea se construye lógicamente en las ciudades, puntos de encuentro, de innovación, de difusión y de integración. Europa vive y se expresa por medio de sus ciudades" (Manifiesto, 1989: p. 15). Y en esa misma reunión Jordi Borja concluía: “... apostar por la ciudad significa también jugar por la integración de sus ciudadanos en ella, por un marco de derechos sociales y políticos y de valores de solidaridad y de apertura, que permitan a la urbe cumplir con su vocación ideal de progreso y tolerancia para todos. Por todo ello es hoy de gran actualidad la política social urbana a escala europea" (1991: p. 21).

Sin duda la integración supone extender los derechos ciudadanos a los migrantes, así como impulsar políticas sociales urbanas que enfrenten las tendencias a la dualización y a la exclusión social, lo cual entra en contradicción con el achicamiento en funciones y recursos del estado de bienestar.

Las tres dimensiones de la ciudadanía que identificó históricamente T.H. Marshall en los años '50 están materializadas en las condiciones de vida que ofrecen las ciudades europeas a la mayoría de sus habitantes. La ciudadanía civil asociada a derechos propios de la libertad individual (igualdad ante la ley, libertad de palabra, de pensamiento, de religión, de propiedad física); la ciudadanía política que se sustenta en los principios de la democracia liberal del derecho a la participación de ser elector y ser elegido, al sufragio universal; y la ciudadanía social que refiere a los derechos a la salud, a la educación, la vivienda, a la seguridad social, sobre los que se constituyó y expandió el estado de bienestar en los países del mundo occidental, sobre la base de adoptar en la posguerra los principios de universalidad.

En América Latina la situación es sustancialmente diferente puesto que la construcción de la ciudadanía, en una o varias de estas dimensiones, es un proceso en marcha de acuerdo con su historia particular. Hubo países donde se alcanzaron estos objetivos en mayor grado, como fue la Argentina de los años '40, pe- 
ro siempre se logró mejor nivel de vida en las ciudades que en el medio rural, en la ciudad "primada" y/o en unas pocas ciudades.

La crisis del modelo del estado de bienestar, nunca plenamente desarrollado, puso en cuestión la misma concepción de ciudadanía que subyacía en su constitución, la determinación de las prestaciones sociales cubiertas por los seguros, y la presencia de los sindicatos en su administración y gestión. Y frente a ello aún no existen nuevos modelos de bienestar a partir de los cuales abordar la cuestión social.

En Europa, dados los cambios demográficos a los que ya se hizo referencia, se considera que hoy "el reto de las políticas sociales en las grandes ciudades es dar el salto de los derechos individuales a los derechos colectivos, en un proceso de modernización social, de lucha contra la exclusión, que integre a los habitantes, las asociaciones, los trabajos y profesionales de los diferentes servicios municipales y del Estado, y que se despliegue su actividad en un frente amplio: el hábitat, la formación, la inserción social, el desarrollo cultural, la comunicación y la recuperación económica" (Fernández, 1991: pp. 57).

Esta reconstitución de la ciudadanía sólo es posible en el ámbito de las ciudades.

Como se ha expresado, la ciudadanía no puede sustraerse a la dimensión espacial que encierra la política. "La familiaridad es el ámbito de la democracia y la ausencia de ésta puede atribuirse entre otras cosas a la extensión de la comunidad y la centralización política que va desmembrando el poder ciudadano" (Silva Herzog, 1996). Precisamente en esto radicaba la profecía de Alexis de Tocqueville (1978) de que el gobierno local era la mejor escuela de la democracia, porque supone que a través de la participación en los asuntos locales, el ciudadano comprende prácticamente sus derechos y responsabilidades, se familiariza con las reglas del juego democrático, y cultiva en sí el respeto por las instituciones.

Por ello, es en el ámbito local donde el ejercicio de la ciudadanía tiene mayores posibilidades de ser efectivo. Es en el barrio, la colonia, los municipios que forman parte de la ciudad, donde los individuos acceden, en condiciones diferenciales, a bienes y servicios que conforman la dimensión social de la ciudadanía, que definen la calidad de vida que ofrece la ciudad.

En América Latina en general, la limitada institucionalización de la participación ciudadana ${ }^{15}$, o su subordinación a las formas de representación corporativas, han generado un excesivo burocratismo y un alto grado de discrecionalidad en los procesos de toma de decisiones, los cuales son indicadores de la baja calidad de la democracia. La creación de una forma de gobierno que ha sido caracterizada como estatal corporativa se correspondió con una "ciudadanía segmentada" (Draibe, 1993) que diferenció a: 1) aquellos que podían acceder a los bienes urbanos por la vía del mercado (vivienda) y pagar contribuciones por los 
servicios públicos suministrados por el gobierno local (recolección de basura, suministro de agua potable, etc.) por contar con un ingreso adecuado; 2) los que poseían la condición de trabajadores asalariados y fueron incorporados a la acción de instituciones gubernamentales (ej.: los organismos de vivienda para los asalariados); 3) una gran mayoría que debió resolver de manera precaria y paupérrima el vivir en la periferia, soportando todo tipo de carencias en relación con el acceso a los bienes urbanos más elementales.

Los ciudadanos y las organizaciones sociales que demandan aún la atención de sus necesidades urbanas básicas dedican grandes esfuerzos y tiempo para identificar a los interlocutores gubernamentales con capacidad e interés en resolver sus demandas. La complejidad y la ineficiencia burocráticas, así como la falta de información respecto a los criterios de asignación de recursos y/o definición de prioridades en las instituciones del aparato gubernamental para tratar asuntos de interés público, son indicadores de la debilidad de las democracias latinoamericanas y de los obstáculos que existen para que la ciudadanía pueda ejercer sus derechos sociales (algunos de los cuales están consagrados en las respectivas constituciones). A esta situación debe atribuirse, en parte, el que durante décadas la forma de relación de los movimientos urbanos autónomos y las instituciones del estado fuese de enfrentamiento y lucha, y que sólo recientemente la apertura democrática favorezca la aparición de una cultura de la negociación entre las partes, que permita buscar soluciones a los graves problemas que presentan estas metrópolis.

Pero existen expectativas y experiencias innovadoras que demuestran la aportación de diferentes formas de participación ciudadana que se han incorporado en los procesos de democratización de los aparatos o instituciones del estado, lo cual permite hacer del espacio de lo estatal un espacio público. Estas formas de participación, sustancialmente diferentes a la participación corporativa que existió durante muchas décadas, sientan nuevas bases para consolidar una gobernabilidad democrática.

Sin duda, los gobiernos de las ciudades deben crear las condiciones para que existan espacios de participación ciudadana e instrumentos que permitan efectivizarla. Suelen existir formas institucionalizadas de participación ciudadana reconocidas por las legislaciones locales. Sin embargo, su eficacia es muy limitada si prevalecen en los hechos formas de gobierno burocráticas y autoritarias que excluyen o subordinan la participación de la ciudadanía en los asuntos públicos. Así, es posible identificar en las ciudades distintos instrumentos -audiencias públicas, referéndum, plebiscito, iniciativa popular-, algunos de los cuales jamás han sido activados aun cuando existan en los respectivos cuerpos legislativos (Ziccardi, 1996). 
Durante varias décadas la responsabilidad sobre las políticas urbanas se restringió al ámbito de lo estatal, y diferentes actores trataban de incidir por vías formales e informales para que sus intereses fueran tomados en cuenta. Los procesos de democratización política y de reforma del estado, los cambios en las fronteras entre lo público y lo privado, y sobre todo las crecientes demandas de la ciudadanía, obligan a construir un nuevo escenario para el diseño y la aplicación de las políticas sociales y urbanas. Actualmente no basta asignar recursos apelando a criterios de racionalidad técnica para mejorar la calidad de vida de nuestras ciudades, sino que es necesario generar posibilidades reales de participación ciudadana en la esfera de lo público.

Nuestras ciudades se caracterizan por la marcada desigualdad que existe para que la población acceda a bienes y servicios básicos. La segmentación social y la segregación urbana, que en los países desarrollados suelen atribuirse a la aplicación de modelos económicos neoliberales, han sido en nuestras ciudades rasgos constitutivos de las mismas.

Se afirma, con razón, que ha habido un paulatino mejoramiento en los niveles de dotación de infraestructura básica, en el acceso y la calidad de las viviendas, en la provisión de equipamiento urbano. Pero es mucho lo que resta por hacer para que habitemos espacios en los que prevalezcan condiciones materiales y ambientales dignas para el conjunto de la ciudadanía.

La participación ciudadana, a diferencia de otras formas de participación, refiere específicamente a que los habitantes de las ciudades intervengan en las actividades públicas representando intereses particulares (no individuales). Pero para que esta participación sea efectiva, deben generarse compromisos y condiciones institucionales, y existir el convencimiento de que la deliberación pública, la interacción social, la aceptación y el respeto por el pluralismo ideológico, son valores y prácticas positivos y esenciales para vivir en democracia, que pueden y deben ejercerse en primer término en el cotidiano y en el espacio local, donde se da la mayor proximidad entre autoridades y ciudadanos.

La ciudad es, en gran medida, un patrimonio colectivo. Su construcción y conservación requiere del saber de los técnicos, de inversión pública y privada, de gobiernos locales legítimamente constituidos, de funcionarios públicos que actúen con honestidad, de la acción de organizaciones sociales y de ONGs que han demostrado su capacidad para transformar y mejorar las condiciones de vida de los sectores populares. Las formas de participación ciudadana debe contemplar necesariamente esta complejidad social para garantizar su eficacia.

Hoy se advierte una recuperación de la identidad de 'ciudadano', y en algunas ciudades una mayor presencia de estructuras institucionales de participación: comités de vecinos de manzanas, colonias, barrios, donde se procesan las demandas de la ciudadanía por bienes y servicios urbanos y que son sus intermediarios 
ante el gobierno local. Pero es interesante señalar que en algunas ciudades se han dado experiencias de participación directa de la ciudadanía tales como las sesiones abiertas de cabildo o las audiencias públicas, como por ejemplo las reuniones donde se discute el "orçamento participativo" en las ciudades brasileñas en las que gobierna el PT.

Sin embargo, durante años, el crear vías institucionales para la participación social no ha garantizado que los ciudadanos sean protagonistas del diseño y la formulación de las políticas locales. Por el contrario, se trató únicamente de un intento de legitimar ciertas políticas formuladas por la burocracia, tanto del gobierno local como de otras instancias de gobierno.

Para ello debemos transitar por el camino de construir ciudadanía: de hacer, de los habitantes de las ciudades, ciudadanos. Ciudadanos con derechos individuales y políticos, pero también con derechos urbanos, derechos a acceder a bienes y servicios básicos, cuyo ejercicio está reconocido por lo general por las leyes supremas de los países.

\section{Los nuevos intermediarios}

La organización social ha sido un componente fundamental en la producción del espacio urbano latinoamericano, particularmente en aquellas ciudades en las que vive un elevado número de familias de las clases populares en forma precaria, como es el caso de São Paulo, Río de Janeiro, Ciudad de México, Guayaquil, Lima, Bogotá. Através de diferentes procesos y modalidades sobre los cuales existe una abundante bibliografía, se puede corroborar cómo las clases populares y sus organizaciones sociales fueron en gran medida los productores del espacio urbano. Así, las organizaciones y movimientos urbanos de favelados, colonos, villeros, pobladores, han demostrado su capacidad para enfrentar la adversidad en el medio urbano a través de: 1) organizar el trabajo colectivo para la autoconstrucción y la introducción de servicios básicos; 2) actuar como intermediarios y gestores ante las autoridades competentes; 3) ser un espacio para la formación y desarrollo de líderes populares.

En su interior suelen existir agrupaciones de madres de familia con demandas de alimentos, escuelas, guarderías, de colonos sin casa, de pobladores que requieren regularizar sus tierras, etc. Sus interlocutores son por lo general las instituciones gubernamentales, tanto de nivel central como local, según el tipo de demanda. Sus luchas han sido ampliamente documentadas y su capacidad de apelar a diferentes recursos les ha permitido sobrevivir en la adversidad.

Por otra parte, para los asalariados, fueron los sindicatos los que se encargaron durante varias décadas de negociar un salario indirecto que les permitía mejorar sustancialmente su nivel de vida (sistemas de atención a la salud, guarderías, clubes, etc.). 
También los partidos políticos de origen popular incorporaron la cuestión social aunque fuese de manera desterritorializada, con escasas referencias al mundo de lo rural y lo urbano. Pero esta acumulación de experiencias permitió que, al triunfar la oposición en las elecciones para gobernar importantes ciudades, se desarrollaran interesantes experiencias de planeación y acciones urbanas adoptando innovadores instrumentos de participación social. A pesar de ello, algunas evaluaciones preliminares señalan las dificultades de transformar la retórica partidaria de la ciudad para todos en políticas e instrumentos eficaces para lograr la integración social y urbana del conjunto de la ciudadanía (Jacobi, 1995).

Otro espacio político importante para la gestión de los bienes y servicios urbanos en nuestras ciudades es el de la representación política: los Consejos y/o Cámaras locales, en los cuales se da una actuación de los representantes políticos de tipo normativa, reglamentaria o legal, a la vez que sus miembros suelen cumplir funciones de gestoría actuando como intermediarios entre la población, el gobierno local y central. Aquí también se advierte la dificultad de concebir a la ciudad de manera integral y superar las políticas clientelares que forman parte de la cultura política en la región. La tendencia es a sectorializar la cuestión social y las políticas que deben atenderla, y a politizar las demandas.

Pero actualmente los cambios económicos y políticos originan una situación diferente, que se caracteriza por la pérdida de representatividad de las organizaciones sindicales y la crisis del estado de bienestar. Esto obliga a reconocer la existencia de nuevos intermediarios sociales entre las instituciones gubernamentales y la ciudadanía, y a revalorizar el papel de la sociedad civil en la implementación de las políticas sociales, entre éstas las urbanas. Las profundas transformaciones que se advierten en la relación sociedad y Estado, las nuevas y diferentes formas de producir bienes y servicios, los cambios en la morfología social, son procesos que se concentran en las mega-ciudades, donde se experimentan rápidos e intensos procesos de desindustrialización y terciarización de la economía. Ello, como se dijo, conlleva a la pérdida de un considerable número de empleos asalariados y estables, la proliferación de actividades informales, y el consiguiente debilitamiento de la representación sindical.

En consecuencia, los gobiernos de las ciudades latinoamericanas son y tienen nuevos interlocutores. Por ejemplo, la presencia de los vendedores ambulantes se da en casi todos los centros de las ciudades y constituye uno de los principales problemas (no estrictamente urbano, sino económico y social) que deben enfrentar los gobiernos locales.

Aun cuando es muy limitada la posibilidad de que los gobiernos de las ciudades participen en la elaboración de políticas económicas, el gobierno local deberá formular una política, ya que los sectores populares reclaman su derecho al trabajo, y el comercio establecido, que paga impuestos, reclama el ejercicio de 
la autoridad. La cuestión entonces es: ¿cómo conciliar intereses tan contradictorios sin debilitar al gobierno local? Para ello las autoridades locales, sin tener facultades legales ni recursos suficientes, diseñan programas puntuales (por ejemplo, re-localización de ambulantes, construcción de nuevos mercados) que no resuelven el problema de fondo (el desempleo o subempleo urbano) pero que contribuyen a disminuir el conflicto social. También hay casos en los que diseñan alguna estrategia de fomento económico de corto plazo por medio de la cual se intenta hacer públicas las condiciones de competitividad que ofrecen el territorio y la sociedad local (por ejemplo, abundante y calificada mano de obra, disponibilidad de infraestructuras, proximidad con grandes centros de comercialización y consumo de productos, puertos para la exportación).

Otro dato de la realidad son los cambios demográficos que deben ser considerados por la autoridad local en sus políticas urbanas. Los jóvenes reclaman fundamentalmente empleos con una remuneración adecuada, pero también demandan espacios deportivos y de recreación; por ello, deben tener garantizados espacios en las estructuras de representación social que existen en la ciudad.

La población flotante, aquella que ingresa diariamente por razones de trabajo y que vive en la periferia o inclusive en la provincia y se traslada por vía área (ej. ejecutivos, empresarios, políticos), genera demandas urbanas. A ello se agrega diariamente la población procedente del exterior, ya sea por motivos de trabajo o de turismo. Todos estos flujos de población que no vive en la ciudad pero que la usa suponen una elevada demanda de bienes y servicios, lo cual debe contemplarse al diseñar las políticas sociales urbanas.

También nuevas generaciones de profesionales reclaman lugares en el mundo del trabajo y espacios de participación social y política local, y deben ser incorporados a la creación de consejos o comités que inciden en diferente grado en el diseño de las políticas públicas dentro de la ciudad.

Las reivindicaciones ciudadanas en torno a problemas ambientales es otra cuestión que permite observar la presencia de nuevos actores sociales que participan autónomamente, e indican la importancia que encierra la cuestión ambiental y la defensa que hace la ciudadanía de la misma, independientemente de su posición económica y social. En este campo, como en otros, han surgido de la ciudadanía organizaciones no gubernamentales en las que profesionales y técnicos cumplen funciones de apoyo a la comunidad. En los últimos años, en el contexto de la reforma del estado, su actuación ha sido legitimada por las instituciones de la política social en general y de las políticas urbanas en particular ${ }^{16}$.

Sin duda existe una amplia gama de nuevos intermediarios sociales que poseen legitimidad ante las instituciones gubernamentales, las organizaciones comunitarias de base (OCB), las organizaciones naturales (vecinales, políticas, sociales), y las ONGs. 
Estas últimas son las que han adquirido mayor visibilidad social, y según Francisco Vío Grossi (1989) son "un tipo particular de organizaciones que no dependen económica, ni institucionalmente del estado, que se dedican a tareas de promoción social, educación e investigación/experimentación, sin fines de lucro, y cuyo objetivo final es el mejoramiento de la calidad de vida de los oprimidos" (Carrión, 1998).

Ahora bien, las ONGs en la realidad de las ciudades latinoamericanas son mucho más que eso. Y sólo se pueden comprender los logros actuales si se tienen presentes los obstáculos y dificultades que debieron vencerse para que estos actores colectivos fueran considerados interlocutores por parte de los organismos gubernamentales con capacidad técnica, operativa y moral. Castells, varias décadas después de haber demostrado la importancia que encerraban las organizaciones sociales urbanas, reafirma que las comunidades pobres que han participado en una supervivencia colectiva (como es el caso de las cocinas comunales en Santiago de Chile o Lima o las comunidades de base en São Paulo), ante la ausencia de políticas públicas responsables, han construido "su propio estado de bienestar". En estas experiencias se reconoce el aporte de las ONGs, algunas de ellas con apoyo internacional como en Bogotá, donde lograron insertarse en las comunidades locales, muchas veces apelando a una identidad religiosa y cumpliendo un papel estratégico para la supervivencia de las clases populares (1997: p. 86).

Entre los papeles que desempeñaron las ONGs en las políticas sociales urbanas, se pueden mencionar: su contribución para desarrollar el potencial de la gente; su capacidad para mejorar su vivienda y sus barrios para satisfacer sus necesidades sociales, económicas y culturales básicas; sus esfuerzos para contribuir al desarrollo democrático que respete los derechos humanos, entre los cuales se destaca el derecho a un lugar donde vivir con paz y dignidad. También debe mencionarse su capacidad para influir en la orientación de políticas y estrategias relativas a los asentamientos humanos, a partir de considerar los aprendizajes que se desprenden de las acciones realizadas por la gente, las ONG y las OCB (1998: pp. 11 y 12).

Pero debe señalarse que el espacio ocupado ahora por las organizaciones no gubernamentales es mucho más importante que el de hace unos veinte años atrás en los tiempos de Hábitat I, celebrado en 1976 (Audefroy, 1998: p. 82). Hoy se advierte la intención de incorporar su actuación en programas y así potenciar recursos sociales diversos. El Banco Mundial ha promovido una Red sobre Reducción de la Pobreza y mantiene una política de incluir a las ONG en las actividades financiadas por el banco, las cuales según un informe participaron en $47 \%$ de sus operaciones y gestión económica (Banco Mundial, 1997). Por su parte, la OCDE, CAD ha creado la llamada "Shaping the 21st century" (Configuración del Siglo XXI). Pero para que esto otorgue mayor eficacia y eficiencia a las políticas sociales, es necesario construir una nueva institucionalidad que facilite las 
Alicia Ziccardi

nuevas formas de actuación entre lo gubernamental, lo privado y lo social. En algunos países desarrollados, los procesos de descentralización y desmantelamiento del estado de bienestar favorecen que el gobierno comparta la responsabilidad social con los llamados organismos intermedios, a fin de potenciar los recursos del gasto público, cada vez más recortados en la materia. Pero en general, en América Latina sólo se observa que esta asociación entre lo gubernamental y lo no gubernamental está aún bastante lejos de lograrse de manera plena para cumplir con objetivos de eficacia social.

Por lo general, es el poco y/o puntual reconocimiento que suele dar la burocracia, por más progresista que sea, al papel que pueden desempeñar los usuarios, destinatarios, involucrados y también a las ONGs, etc. para hacer de la acción gubernamental precisamente lo que debiera ser una acción pública y no sólo estatal. Esto a pesar de que se advierte que son: i) facilitadoras y consultoras técnicas, entre el gobierno y las OCB, ii) instancias con capacidad de influenciar en políticas y programas, iii) asumen múltiples papeles, de emprendedoras y/o empresariales, y brindan apoyo a las agencias gubernamentales para la institucionalización de sistemas de planificación y provisión de servicios de naturaleza más participativa (Metha Meera, 1998).

Según Joel Audefroy (1998), existen ya experiencias participativas institucionalizadas exitosas llevadas a cabo por ONGs y organizaciones sociales. Respecto de estas últimas ejemplifica con los casos de Dominicana, Chile y Bolivia, donde el medio utilizado fue el involucrar a funcionarios del gobierno en procesos participativos, algunos de los cuales provenían de ONGs; Sao Paulo o Lima, donde las propuestas surgieron de ONGs y de organizaciones sociales en el ámbito de la planificación local o regional; o Ciudad de México, donde las ONGs utilizaron el poder de los medios de comunicación de masas para influir en las políticas (por ejemplo, en el caso del Superbarrio, personaje creado por el movimiento urbano popular del centro de la Ciudad de México).

Por otra parte, su papel fue importante en aquellos países en los que existían partidos políticos débiles, e inclusive contribuyeron a su constitución cuando en los ochenta se restauraron los regímenes democráticos. Este es el caso de las vinculadas a comunidades eclesiales de base, que alimentaron el PT en las ciudades brasileñas, o las organizaciones que formaban parte del movimiento urbano popular y que aportaron sus líderes y sus miembros al PRD, en la Ciudad de México.

Lo cierto es que, a fin del siglo XX, en las ciudades latinoamericanas la organización social se considera un recurso, un capital social importante, en particular para que los grupos más vulnerables de la población hagan frente a sus dificultades. 


\section{Bibliografía}

Autores varios 1998 Construyendo la ciudad con la gente, Nuevas tendencias en la colaboración entre las iniciativas comunitarias y los gobiernos locales (México: Habitat International Coalition -HIC-).

Abranches, Henrique; Sérgio, Wanderley; Guilherme dos Santos y Marcos Antônio Coimbra 1994 (3 ra.)"Polìtica social e combate à pobreza" (Rio de Janeiro: Jorge Zahar).

Aguilar, Adrián y Boris Grraizbord 1992 "Las ciudades medias y la política urbano-regional. Experiencias recientes en México”, en Investigaciones geo gráficas (México, UNAM) Boletín del Instituto de Geografía, No especial.

Alburquerque, Francisco 1993 "Pautas de localización y desarrollo territorial en la comunidad Europea", en EURE, Revista Latinoamericana de Estudios Urbanos Regionales, Instituto de Estudios Urbanos de la Pontificia Universidad Católica de Chile, Vol. XIX, Julio, Nº 57, pp. 59-79.

Audefroy, J. 1998 "Lecciones y propuestas", en Ortiz, E. y J. Audefroy (Coordinadores) 1998 Construyendo la ciudad con la gente: nuevas tenden cias en la colaboración entre las iniciativas comunitarias y los gobiernos lo cales (México: Habitad International Coalition México) pp. 78-104.

Ayuntamiento de Barcelona-Eurociudades, Las ciudades y las Políticas sociales en Europa 1991 Congreso Europeo de Bienestar Social (Barcelona). Banco Mundial 1997 Informe Anual 1997 (Washington D.C.) pp. 14-98.

Barbeito, A. y Rubén M. Lo Vuolo 1992 La modernización excluyente: transformación económica y el estado de bienestar en Argentina (Buenos Aires, Unicef, Ciepp y Losada) pp. 221.

Berri, Jeffrey; K. Portney y Ken Thomson 1993 The rebirth of urban demo cracy (The Brookings Institution: Whashington D.C.).

Borja, Jordi y Manuel Castells 1997 Local y Global: la gestión de las ciu dades en la era de la información United Nations for Human Settlements (UNCHS) (Madrid: Taurus) pp. 418.

Borja, Jordi 1991 "Las ciudades y las políticas sociales en Europa: Introducción”, para el Congreso Europeo de Bienestar Social (Barcelona: Barcelona-Eurociudad, editada, Ajuntament de Barcelona) No 4, pp. 15-21.

Borja, Jordi (Editor) 1995 "Barcelona. Un modelo de transformación urbana”, en Serie de Gestión Urbana (Quito) Vol. 4, PGU-LAC, Programa de Gestión Urbana; Ajuntament de Barcelona, pp. 287.

Carrión, M., Diego 1998 “Repensando la cuestión del hábitat popular en las ciudades del Tercer Mundo: es la hora de corresponsabilidades”, en Ortiz y Audefroy (Coordinadores) ob. cit. México, pp. 18-36. 
Alicia Ziccardi

Castells, Manuel 1997 "La era de la información. Economía, Sociedad y Cultura" (Madrid: Alianza Editorial) Tres Tomos.

CEPAL 1996 Quince años de desempeño económico: América Latina y el Caribe, 1980-1995 (Santiago de Chile).

CEPAL 1997 La brecha de la equidad (Santiago).

Clemente, Adriana 1998 "Participación en políticas sociales y presupuesto municipal", en Revista Pobreza Urbana Desarrollo, Presupuesto Municipal Participativo, año 8 - $\mathrm{N}^{\circ} 17$, Abril.

Comas, Antoni 1991 "Política social y vertebración Europea", en Ayunta miento de Barcelona-Eurociudades, ob.cit., pp. 33-34.

Concha, E. Alberto, Fernando Carrión y Germán Cobo (Editores) 1994

"Ciudad y violencias en América Latina", en Serie de Gestión Urbana

(Quito, Ecuador: PGU-LAC) Vol. 2, , Programa de Gestión Urbana; Alcaldía pp. 324.

Coraggio, José Luis 1998 [a] "La política urbana metropolitana frente a la globalización”, en Coraggio, Jóse Luis Curso de Postgrado en Planifica ción Urbana (Mar del Plata).

Coraggio, Jóse, Luis 1998 [b] "Economía popular urbana: una nueva perspectiva para el desarrollo local", en Gestión y planificación urbana, Curso de Postgrado, Junio-Octubre, (Mar de Plata) pp.127.

Coraggio, Jóse Luis 1998 [c] "El trabajo desde la perspectiva de la economía popular", versión revisada de ponencia presentada en el Seminario Impactos territoriales de la reestructuración laboral, Argentina, San Carlos de Bariloche, Mayo (Mimeo) pp.17.

Cordera, Rolando 1996 "Mercado y equidad: de la crisis del Estado a la política social", en Autores varios Las políticas sociales de México en los no venta, I. Mora (México: UNAM, FLACSO, PyV) pp. 45-59.

Cordera, Rolando y Alicia Ziccardi (Coordinadores) 1999 Las políticas so ciales en México al fin del milenio, descentralización diseño y gestión (México: IIS-Facultad de Economía, UNAM).

Cunill, Nuria 1991 La participación ciudadana (Caracas: Centro Latinoamericano de Administración para el Desarrollo, CLAD).

Dahrendorf, Ralf 1980 "Effectiveness and legitimacy: on the governability of democracies", en The Political Quarteley (Londres) Vol. 51, No 4, Octubre-Diciembre.

Davis, Diane 1994 The urban Leviathan (Filadelfia: Temple University Press).

Dos Santos, Mario 1991 "Gobernabilidad en la transición a la democracia en Argentina", en Revista Mexicana de Sociología (México) № 1 . 
Draibe, Sonia 1993 "Qualidade de vida e reformas de programs sociais: o Brasil no cenario latinoamericano", en Lua Nova (São Paulo) No 31 .

Fainsten, Susan, Ian Gordon y Michel Harloe 1992 Divided cities, New York and London in the contemporary world (Oxford, Cambridge: Blackwell).

Fitoussi, Jean-Paul y Pierre Rosanvallon 1997 La nueva era de las desi gualdades (Buenos Aires: Editorial Manantial) pp. 238.

Franco, Rolando 1997 "Paradigmas de la política social en América latina", en Menjívar et al op. cit. (Costa Rica) pp. 35-59.

García Canclini, Néstor 1995 Consumidores y ciudadanos (México: Grijalbo).

García Canclini, Néstor (Coordinador) 1998 Cultura y comunicación en la Ciudad de México (México: UNAM- Grijalbo) 2 tomos.

García, Reyes Miguel y María M. Agudelo de Latapí 1997 Ajuste estructu ral y pobreza: la transición económica en la sociedad mundial contempo ránea (México: Instituto Tecnológico y de Estudios Superiores de Monterrey (ITESM), Campus Ciudad de México y Fondo de Cultura Económica) pp. 375.

Gilbert, Alan 1993 "Ciudades del tercer mundo: la evolución del sistema nacional de asentamientos", en EURE, Revista Latinoamericana de Estu dios Urbanos Regionales (Chile: Pontificia Universidad Católica de Chile), Instituto de Estudios Urbanos, Vol. XIX, Julio, No 57 pp. 41-59.

Instituto Federal Electoral 1998 "Las modalidades del voto de los mexicanos residentes en el extranjero", en Informe Final de la Comisión (México). Jacobi, Pedro 1995 "Alcances y límites de los gobiernos locales progresistas en Brasil. Las alcadías petistas", en Revista Mexicana de Sociología (IIS-UNAM, México) Año LVII, No 2, Abril-Junio.

Jacobs, Brian 1992 "Fractured Cities. Capitalism, community and empowerment in Britain and America" (Londres y Nueva York: Routledge) p. 302.

Landáburo, Eneko 1991 "Integración económica y social y desarrollo urbano", en Ayuntamiento de Barcelona-Eurociudades, op. cit. pp. 29-32.

Londoño, Juan Luis 1996 "Pobreza, desigualdad y formación del capital humano en América Latina, 1950-2025", en Estudios del Banco Mundial sobre América Latina y el Caribe (México) pp. 39.

Lustig, Nora (Comp.) 1997 "El desafío a la austeridad: pobreza y desigualdad en América Latina", en El trimestre económico (México: Fondo de Cultura Económica) No 86, pp. 491.

Lustig, Nora y Ruthanne Deutsch 1998 El Banco Interamericano de Desa rrollo y la reducción de la pobreza. BID (Washington: Mimeo) pp. 36.

Maldonado, Luis 1998 "Desarrollo regional y combate a la pobreza", en Examen, $\mathrm{N}^{\circ}$ 110, Diciembre, pp. 41-50. 
Marshall, T.H. 1950 Citizenship and social class, and other essays (University of Cambridge) pp. 154.

Martínez, Assad, Carlos y Alicia Ziccardi 1992 "Propuestas de descentralización del Estado mexicano", en Carlos Bazdresch et al, México, auge, cri sis y ajuste (México: Fondo de Cultura Económica).

Mehta, Merra 1998 "Panorama general de los estudios de caso en cinco regiones", en Autores Varios Construyendo la ciudad con la gente, Nuevas tendencias en la colaboración entre las iniciativas comunitarias y los go biernos locales (México: Habitat International Coalition -HIC-) Cap. 1, pp. 37-77.

Ménjivar, Dirk y Lieteke (Coordinadores) 1997 Pobreza, exclusión y políti ca social (Costa Rica: FLACSO).

Minujin, Alberto (Coordinador) 1993 [a] Cuesta Abajo. Los nuevos pobres: efectos de la crisis en la sociedad argentina (Buenos Aires: Unicef - Losada) p. 287.

Minujin, Alberto (Editor) 1993 [b] Desigualdad y exclusión: desafios para la política social en la Argentina de fin de siglo (Buenos Aires: Unicef Losada) p. 227.

Neira Alva, Eduardo (Coordinador) 1996 "El desarrollo sustentable y las metrópolis latinoamericanas", en Segundo Foro del Ajusco (México, D.F.: El Colegio de México, PNUMA) p. 156.

OCDE 1997 Estudios económicos, 1996-1997 (México).

O’ Donnell, Guillermo 1993 “Estado, democratización y ciudadanía”, en Nueva Sociedad (Caracas) No 128, Noviembre-Diciembre.

ONU 1997 [a] Informe sobre la situación social en el mundo, 1997 (Departamento de Información Económica y Social y de Análisis de Políticas, Naciones Unidas: Nueva York).

ONU 1997 [b] “Informe sobre desarrollo humano, 1997”, publicado para el Programa de las Naciones Unidas para el Desarrollo (PNUD) (Madrid: Ed. Mundi-Prensa) p. 262.

Ortiz, E. y J. Audefroy (Coordinadores)1998 Construyendo la ciudad con la gente: nuevas tendencias en la colaboración entre las iniciativas comu nitarias y los gobiernos locales (México: Habitad International Coalition -HIC) p. 267.

Pacini, Marcello et al, 1993 "La capitale reticolare" (Torino: Edizione della Fondazione Giovanni, Agnilli).

Provencio, Enrique 1990 "Pobreza, Política económica y política social”, en Autores Varios México: la búsqueda de alternativas, de Cultura Popu lar, CEPNA (México: Facultad de Economía, UNAM). 
Autores Varios 1990 México: la búsqueda de alternativas, de Cultura Po pular, CEPNA (México: Facultad de Economía, UNAM).

Quinti, Gabriele 1997 "Exclusión social: sobre medición y sobre evaluación”, en Ménjivar, Dirk y Lieteke (Coordinadores) Pobreza, exclusión y política social (Costa Rica: FLACSO) pp. 71-93.

Reilly, Charles (Compilador) 1994 Nuevas politicas urbanas. Las ONG y los gobiernos municipales en la democratización latinoamericana (Virginia: Fundación Interamericana).

Rosanvallon, Pierre 1995 La nueva cuestión social (Buenos Aires: Argentina) p. 215.

Safa, Patricia 1998 “ Identidades locales y multiculturalidad: Coyoacán”, en García Canclini, Néstor (Coordinador) Cultura y comunicación en la Ciu dad de México (México: UNAM- Grijalbo) pp. 278-319.

Silva-Herzog Márquez, Jesús 1996 "Esferas de la democracia”, en Cuader nos de Divulgación de la Cultura Democrática Instituto Federal Electoral, $\mathrm{N}^{\circ} 9$.

Toqueville, Alexis de 1978 La democracia en América (México: Fondo de Cultura Económica).

Tomassini, Luciano 1993 Estado, gobernabilidad y desarrollo, BID (Washington) I serie Monografía, No 9.

Vadershuren, Franz Rol 1995 "Rol de las municipalidades en el apoyo al sector informal de la economía", en Os Desafios de cidade informal (Belo Horizonte: Seminario Internacional, Belo Horizonte) pp. 231-239.

Autores Varios 1995 “¿Descentralizar en América Latina?”, en Programa de Gestión Urbana (Quito: Banco Mundial, GTZ, UNCHS, PNUD).

Vintro, Eulália 1991 "La unificación europea, la política social y las ciudades", en: Ayuntamiento de Barcelona-Eurociudades, op. cit., pp.25-27.

Ward, Peter 1991 México: una megaciudad, producción y reproducción de un ambiente urbano CONACULTA (México: Alianza Editorial).

Welti, Carlos (Coordinador) 1996 "Dinámica demográfica y cambio social", presentado en el XX Congreso de la Asociación Latinoamericana de Socio logía (México-Unam: Ed. Programa Latinoamericano de Actividades en Población -PROLAP) pp. 383.

Zaluar, Alba 1994 "La droga, el crimen, el diablo, São Paulo", en Autores Varios Ciudad y violencias en América Latina (Quito) Programa de Gestión Urbana, pp. 235-254.

Autores Varios 1994 Ciudad y violencias en América Latina (Quito) Programa de Gestión Urbana. 
Alicia Ziccardi

Ziccardi, Alicia 1983 "Villas miseria y favelas: sobre las relaciones entre las instituciones del Estado y la organización social en las democracias de los años sesenta", en Revista Mexicana de Sociología (Instituto de Investigaciones Sociales, UNAM, México) Año XLV, № 1, Enero-Marzo.

Ziccardi, Alicia (Coordinadora) 1996 (2 da.) La tarea de gobernar: gobier nos locales y demandas ciudadanas (México: Instituto de Investigaciones Sociales-UNAM y Miguel Ángel Porrúa).

Ziccardi, Alicia 1995 [a] "Gobiernos locales: entre globalización y ciudadanía (reflexiones sobre las transformaciones recientes en el DF)", en Calva, J.L. y A. Aguilar (Coordinadores) Desarrollo regional y urbano, Tendencias y alternativas (México: CIIH; Instituto de Geografía - UNAM) Tomo I.

Ziccardi, Alicia 1995 [b] "La gobernabilidad de la metrópolis latinoamericanas", en Neira Eduardo (Coordinador) La sustentabilidad de las metropólis latinoamericanas (México: Foro Ajusco II, PNUMA, COLMES).

Ziccardi, Alicia 1997 "El papel de los gobiernos municipales en las políticas sociales", en Revista Eslabones (México) N No 13, Enero-Junio.

Ziccardi, Alicia 1998 [a] Gobernabilidad y participación ciudadana en la Ciudad Capital (México: Miguel Angel Porrúa).

Ziccardi, Alicia 1998 [b] "La ciudad capital: hacia una gobernabilidad democrática”, en Muñoz, Humberto (Coordinador) La sociedad mexicana frente al tercer milenio (México: UNAM) (en prensa).

\section{Notas}

1 Estos bienes y servicios colectivos dieron origen a la teoría de los bienes y/o medios de consumo colectivo desarrollada por diferentes corrientes marxistas de la sociología urbana francesa (Castells, Lojkine, Topalov) en los años '70.

2 En las capitales, en las que durante décadas sus ciudadanos no eligieron a sus gobernantes -como son los casos de Buenos Aires y Ciudad de México-, a pocos años de la culminación del siglo XX sus habitantes han recuperado el más fundamental de sus derechos: elegir a través del voto a su jefe de gobierno. En ambos casos triunfaron partidos de oposición.

3 El total mundial pasó de 1.8 entre 1950-1955 a 1.5 entre 1990-1995. Esta tasa se elevó en África de 2.2 a 2.7. Se redujo en cambio en Asia de 1.9 a 1.5, en América del Norte de 1.7 a 1.0, y en Oceanía de 2.2 a 1.4 en los mismos períodos.

4 Se estima que en EUAviven 7.1 millones de migrantes nacidos en México, y 2.6 millones que son hijos de madre y/o padre mexicanos (Instituto Federal Electoral, 1998). 
5 Entre $40 \%$ y $60 \%$ en Asia y más de 60\% en África.

6 Estos son datos de OIT (Cit. CEPAL, 1997: p. 15).

7 Entre el $25 \%$ y el $40 \%$ de los ocupados pobres trabajan como asalariados en microempresas junto con el servicio doméstico (CEPAL, 1997: I -37).

8 En Bolivia y Honduras el porcentaje alcanza al 40\% (CEPAL, 1997: I37).

9 Aunque fluctúa mucho entre países, registrándose menos del 10\% en Argentina y Uruguay, y entre el 30\% y 40\% en Bolivia, Brasil, Colombia, México, Paraguay y Venezuela (CEPAL, 1997: I-35).

10 En 7 de los 12 países examinados, entre $30 \%$ y $50 \%$ de los asalariados del sector privado que trabajan fuera de las microempresas pertenecían a hogares con ingresos inferiores al umbral de pobreza (CEPAL, 1997: I- 37-38).

$11 \mathrm{La}$ ONU afirma que en América Latina y el Caribe la incidencia de pobreza rural (58\%) es 1.8 veces la de la pobreza urbana (33\%) (1997 [b]: pp 51). Por ejemplo, en Brasil la tasa de alfabetización de adultos en el DF era, en 1991, del 91\%, en tanto que en Alagoas era sólo del 55\%.

12 Datos obtenidos de "Survey of Living Coditions in the Metropolitan Area of Sao Paulo" (Ginebra: International Labour Office, International Institute of Labour Studies, 1994) (cit. en Borja y Castells, 1997: p. 73).

13 CEPAL, luego de ofrecer estas cifras absolutas, afirma que hubo un significativo avance en la reducción de la pobreza entre 1990 y 1994, ya que se redujo en 12 países de la región. Cabe resaltar que estas cifras de CEPAL no se corresponden con las estimaciones ofrecidas por Londoño, J. (1996) que presentamos en el capítulo 2 de este trabajo. Tampoco existe coincidencia con el BID, cuyas estimaciones sostienen que 1 de cada 3 personas vive con ingresos inferiores a dos dólares, por lo cual, según esta medición, el número de pobres en América Latina es considerablemente menor, alcanzando a 150 millones de habitantes.

14 Los decretos de congelación de rentas que promulgaron en los años ' 40 en varias ciudades latinoamericanas desalentaron la producción de viviendas en alquiler.

15 En Bolivia se creó hace pocos años una interesante legislación para la participación popular.

16 Sobre el papel de las ONGs y los gobiernos locales en las actuales políticas urbanas en América Latina, véase: Reilly (1994). También Ortiz y Audefroy (Coordinadores), 1998. 